\title{
Reactions of 26-Iodopseudodiosgenin and 26-Iodopseudodiosgenone with Various Nucleophiles and Pharmacological Activities of the Products
}

\author{
Hong-Ji Quan, Jyunichi Koyanagi, Ken Hagiwara, Xing-Ri Cui, Yasunori Isshiki, Seiichi Kondo, \\ Fusao KomadA, and Setsuo SAITo*
}

Faculty of Pharmaceutical Sciences, Josai University; 1-1 Keyakidai, Sakado, Saitama 350-0295, Japan.

Received August 3, 2005; accepted October 12, 2005

26-Iodopseudodiosgenin (8) and 26-iodopseudodiosgenone (9) were reacted with various nucleophiles (KSCN, KOCN, $\mathrm{NaCN}, \mathrm{NaN}_{3}$ and various amines) to give pseudodiosgenin derivatives $(4,12,16-20,26)$ and pseudodiosgenone derivatives $(5,13,21-25,27)$, respectively. The reactions of 8 and 9 with KOCN gave the elimination products (10) and (11), respectively. The reaction of 9 with $\mathrm{NaCN}$ gave $5 \alpha, 26$ - (14) and $5 \beta$,26-dicyanocholestan-3-one (15). The reaction of 8 with $\mathrm{NaN}_{3}$ gave triazepine derivative (30), while that of 9 gave 26-azidopseudodiosgenone (31). Compound 31 was converted into triazepine derivative (32) by heating at $120^{\circ} \mathrm{C}$. The cytotoxicity of the pseudodiosgenins and pseudodiosgenones on P-gp-underexpressing HCT 116 cells and P-gpoverexpressing Hep G2 cells was examined by MTT assay. Pseudodiosgenins 2, 4, 12 and 30 showed strong cytotoxic activity $\left(\mathrm{IC}_{50}\right.$ values: $\left.2.6 \pm 0.3-6.7 \pm 1.4 \mu \mathrm{M}\right)$, as did pseudodiosgenones $3,5,11,13,21-25$ and 27 (IC ${ }_{50}$ values: $\left.1.3 \pm 0.3-6.4 \pm 0.3 \mu_{\mathrm{M}}\right)$ toward HCT 116 cells. Pseudodiosgenins 12,16 and $30\left(\mathrm{IC}_{50}\right.$ values: $1.2 \pm 0.7-$ $2.2 \pm 0.6 \mu \mathrm{M})$ and pseudodiosgenones $22,23,25$ and $27\left(\mathrm{IC}_{50}\right.$ values: $\left.0.6 \pm 0.1-2.5 \pm 0.3 \mu \mathrm{M}\right)$ were highly cytotoxic to Hep G2 cells. Compounds 3 and 27 showed efficient antibacterial activity (MIC: $15.6,10.4 \mu \mathrm{g} / \mathrm{ml}$ ) and (MIC: 7.8, $15.6 \mu \mathrm{g} / \mathrm{ml}$ ) against Bacillus subtilis and Staphylococcus aureus, respectively.

Key words pseudodiosgenin; pseudodiosgenone; cytotoxic activity; P-glycoprotein; antibacterial activity

Saponins have various pharmacological effects such as anti-tumor, ${ }^{1)}$ anti-allergic, ${ }^{2)}$ anti-inflammatory, ${ }^{3)}$ and antiHIV $^{4,5)}$ activity. Previously, we reported the structure-activity relationships for the anti-hepatitis ${ }^{6-12)}$ and anti-HIV activity ${ }^{13)}$ of various glycosides constructed using a combination of different sugars and aglycons synthetically derived from glycyrrhetic acid. ${ }^{14)}$ Furthermore, we compared the cytotoxicity of various synthetic spirostanols and heterospirostanols ${ }^{15)}$ derived from diosgenin (1). In the investigation of cytotoxicity, we found that 26-cyanoselenopseudodiosgenone (3) (an opened F ring structure) showed marked activity. This finding led us to attempt to prepare furostane derivatives having various substituents containing other hetero atoms such as sulfur and nitrogen at position 26 and to evaluate the pharmacological activity. The present study deals with the reactions of 26-iodopseudogiosgenin $(\mathbf{8})$ and 26-iodopsuedogiosgenone (9) with various nucleophiles to obtain various pseudodiosgenin and pseudodiosgeone derivatives, and evaluations of cytotoxicity of the derivatives using cancerous HCT 116 and Hep G2 cells. Furthermore, antibacterial activity against Bacillus subtilis, Staphylococcus aureus, Escherichia coli and Pseudomonas aeruginosa, and antifungal activity against Candida albicans and Aspergillus niger are investigated.

\section{Results and Discussion}

We already reported the synthesis of 26-cyanoselenopseudodiosgenin (2) and 26-cyanoselenopseudodiosgenone $3^{15}$ according to the methods reported by Uhle ${ }^{16-18)}$ with minor modifications. This time, the pseudodiosgenin analogs (4) and (6) and pseudodiosgenone analogs (5) and (7) having a SCN and OCN group, respectively, and pseudodiosgenin and pseudodiosgenone derivatives having various amino substituents at position 26 were prepared. For the synthesis, 26iodopseudodiosgenin $\mathbf{8}$ and 26-iodopseudodiosgenone $\mathbf{9}^{15}$ were used as starting materials. The reaction conditions and products of the reactions of $\mathbf{8}$ and $\mathbf{9}$ with various nucleophiles (runs 1-21) are listed in Table 1.

The reaction of $\mathbf{8}$ with potassium thiocyanate (KSCN) (run
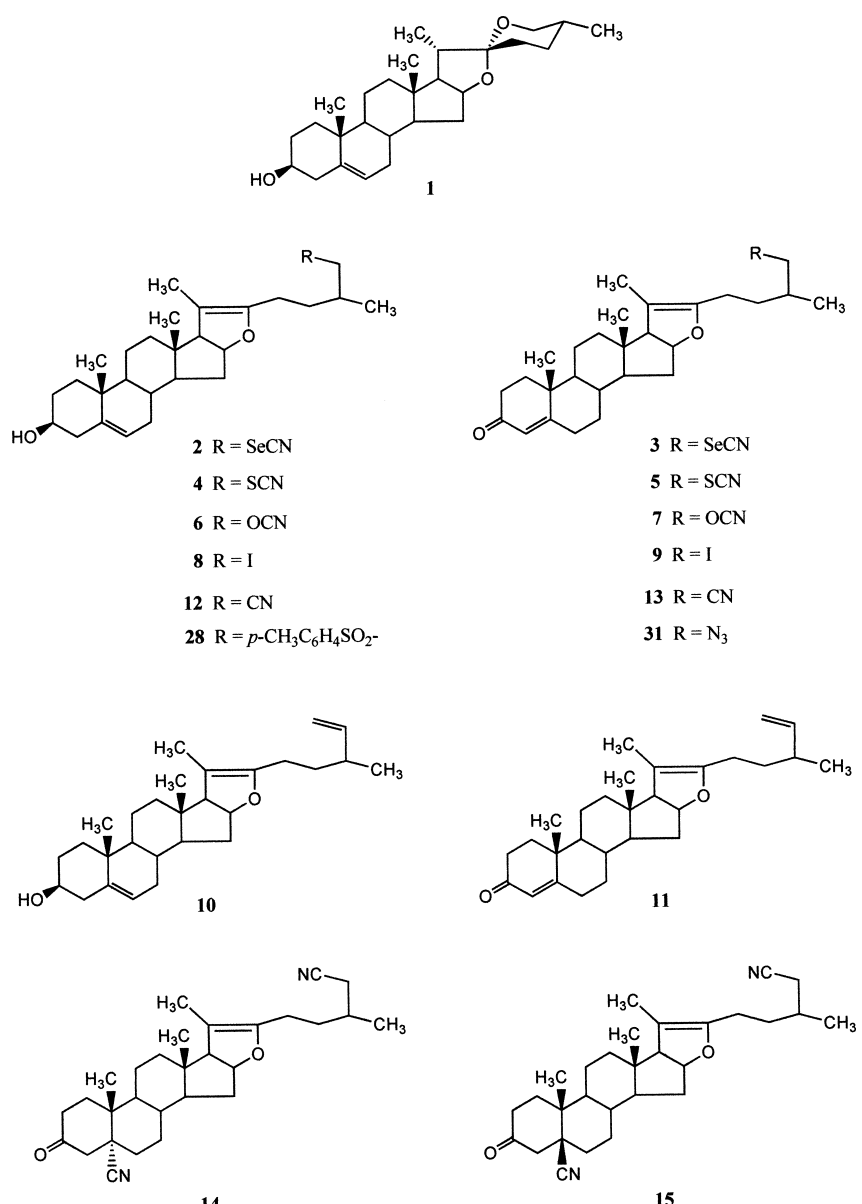

Fig. 1. Structures of Compounds $\mathbf{1}-\mathbf{1 5}, \mathbf{2 8}$ and $\mathbf{3 1}$ 
1) gave 26-cyanothiopseudodiosgenin 4 in $40 \%$ yield. The reaction of 9 with $\mathrm{KSCN}$ (run 11) gave 26-cyanothiopseudodiosgenone $\mathbf{5}$ in $79 \%$ yield.

To prepare compounds 6 and 7, each of the iodides 8 and 9 was reacted with potassium cyanate $(\mathrm{KOCN})$ (runs 2, 12, respectively). However, rather than 6 and 7, the reaction gave the elimination products $\mathbf{1 0}$ and $\mathbf{1 1}$ in yields of 25 and $40 \%$. These results may be due to the weaker nucleophilicity and the stronger basicity of the ${ }^{-} \mathrm{OCN}$ group than ${ }^{-} \mathrm{SCN}$ and - SeCN groups.

26-Cyanopseudodiosgenin (12) and 26-cyanopseudo-
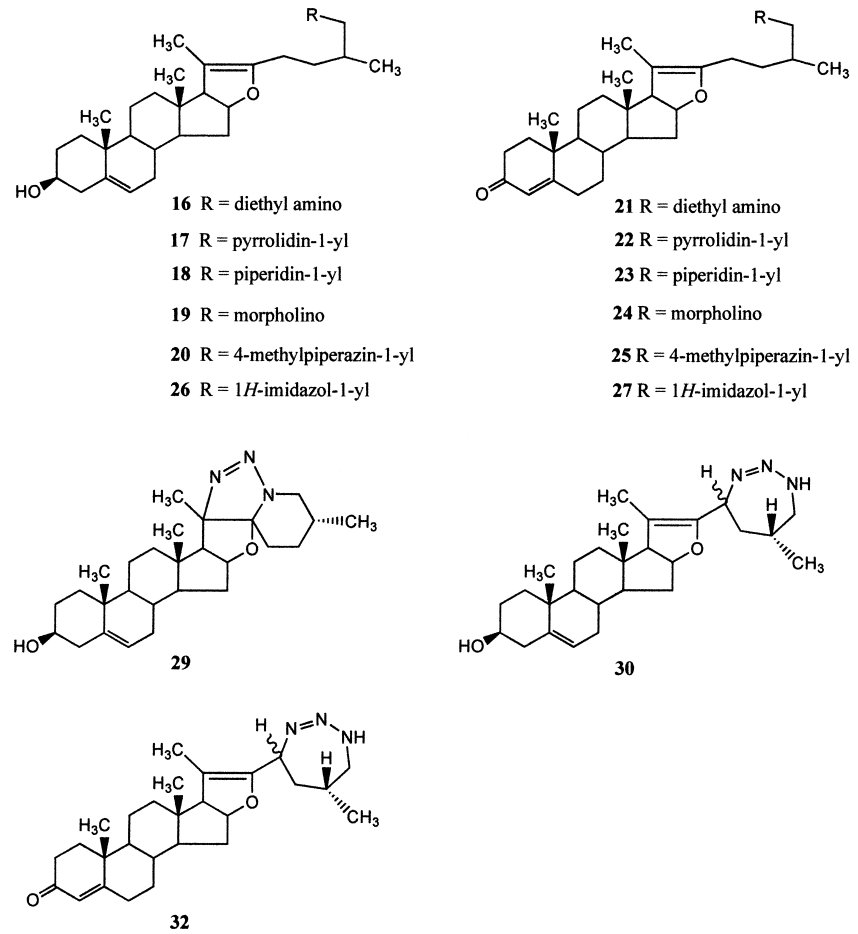

Fig. 2. Structures of Compounds 16-27, 29, 30 and 32 diosgenone (13), which have no $\mathrm{S}$ and Se atoms, were synthesized for comparison of their pharmacological activities with those of $\mathbf{2 - 5}$. The reaction of iodide $\mathbf{8}$ with sodium cyanide $(\mathrm{NaCN})$ at $60{ }^{\circ} \mathrm{C}$ for $16 \mathrm{~h}$ (run 3) gave compound $\mathbf{1 2}$ in $75 \%$ yield. On the other hand, the reaction of iodide 9 with $\mathrm{NaCN}$ at $60^{\circ} \mathrm{C}$ for $12 \mathrm{~h}$ (run 13) gave dicyanides $14(18 \%$ yield) and 15 (18\% yield) and unisolated products. Thus, as the reaction of 9 with $\mathrm{NaCN}$ at $60^{\circ} \mathrm{C}$ for $12 \mathrm{~h}$ gave dicyanides but not monocyanides such as 13 , the reaction was run for less time $(2.5 \mathrm{~h})$ at the same temperature (run 14) to give 13, 14 and 15 in yields of 33, 12 and 17\%, respectively.

The introduction of various amino groups at position 26 of pseudodiosgenins and pseudodiosgonones was performed by reacting iodides $\mathbf{8}$ and $\mathbf{9}$ with several kinds of amines such as diethyl amine, pyrrolidine, piperidine, morphorine, 1methylpiperazine and imidazole as well as sodium azide. All reactions were carried out at $60^{\circ} \mathrm{C}$. The reactions of $\mathbf{8}$ with diethyl amine, pyrrolidine, piperidine, morphorine and 1methylpiperazine (runs 4-8, respectively) gave the corresponding amines 16-20 in yields of 58, 70, 80, 54 and $62 \%$, respectively. The reactions of 9 with diethyl amine, pyrrolidine, piperidine, morphorine and 1-methylpiperazine (runs 15-19, respectively) gave compounds $(\mathbf{2 1 - 2 5})$ in 64,27 , 79,73 and $61 \%$ yields, respectively. The reaction of $\mathbf{8}$ with imidazole in the presence of $\mathrm{K}_{2} \mathrm{CO}_{3}$ (run 9) gave (26) and $\mathbf{1 0}$ in 33 and $47 \%$ yields, respectively, and that of 9 with imidazole in the presence of $\mathrm{K}_{2} \mathrm{CO}_{3}$ (run 20) gave (27) and 11 in 18 and $27 \%$ yields, respectively.

Uhle $^{18)}$ reported that 26- $p$-tosylpseudodiosgenin (28) reacted with sodium azide to give $3 \beta$-hydroxy-22(27)-imino20(N)-azo-25 $\alpha$-5-furostene (29). To obtain 29, iodide 8 was used as a starting material instead of 28; compound $\mathbf{8}$ was reacted with sodium azide at $60^{\circ} \mathrm{C}$ for $12 \mathrm{~h}$ (run 10) according to the method reported by Uhle to give $22-((6 R)-4,5,6,7-$ tetrahydro-6-metyl-1H-1,2,3-triazepine-4-yl)-pseudodiosgenin (30) in $43 \%$ yield, which was a different product from 29. The ${ }^{1} \mathrm{H}-\mathrm{NMR}$ spectrum of $\mathbf{3 0}$ exhibited only one proton

Table 1. The Reaction Conditions and Products of the Substitutions of Compounds 8 and 9 with Various Nucleophiles ${ }^{a)}$

\begin{tabular}{|c|c|c|c|c|}
\hline Run & Substrate & Nucleophile (eq) & Reaction time (h) & Product(s) (\%) \\
\hline 1 & 8 & $\mathrm{KSCN}(4)$ & 12 & $4(40)$ \\
\hline 2 & 8 & $\mathrm{KOCN}(4)$ & 12 & $10(25)$ \\
\hline 3 & 8 & $\mathrm{NaCN}(4)$ & 16 & $12(75)$ \\
\hline 4 & 8 & Diethyl amine (4) & 12 & $16(58)$ \\
\hline 5 & 8 & Pyrrolidine (4) & 1 & $17(70)$ \\
\hline 6 & 8 & Piperidine (4) & 2 & $18(80)$ \\
\hline 7 & 8 & Morpholine (4) & 5 & $19(54)$ \\
\hline 8 & 8 & 1-Methylpiperazine (4) & 4 & $20(62)$ \\
\hline 9 & 8 & Imidazole $(4)^{b)}$ & 3 & $26(33), 10(47)$ \\
\hline 10 & 8 & $\mathrm{NaN}_{3}(4)$ & 12 & $30(43)$ \\
\hline 11 & 9 & KSCN (4) & 12 & $5(79)$ \\
\hline 12 & 9 & $\mathrm{KOCN}(2)$ & 24 & $11(40)$ \\
\hline 13 & 9 & $\mathrm{NaCN}(4)$ & 12 & $14(18), 15(18)$ \\
\hline 14 & 9 & $\mathrm{NaCN}(4)$ & 2.5 & $13(33), 14(12), 15(17)$ \\
\hline 15 & 9 & Diethyl amine (4) & 3 & $21(64)$ \\
\hline 16 & 9 & Pyrrolidine (4) & 2 & $22(27)$ \\
\hline 17 & 9 & Piperidine (4) & 12 & $23(79)$ \\
\hline 18 & 9 & Morpholine (4) & 12 & $24(73)$ \\
\hline 19 & 9 & 1-Methylpiperazine (4) & 12 & $25(61)$ \\
\hline 20 & 9 & Imidazole $(4)^{b)}$ & 3 & $27(18), 11(27)$ \\
\hline 21 & 9 & $\mathrm{NaN}_{3}(4)$ & 12 & $31(61)$ \\
\hline
\end{tabular}

a) Reaction of 9 with $\mathrm{KOCN}$ was performed at $30^{\circ} \mathrm{C}$ (run 12) and the other reactions at $60^{\circ} \mathrm{C} . \quad$ b) Potassium carbonate $(10$ eq) was added in these reactions. 


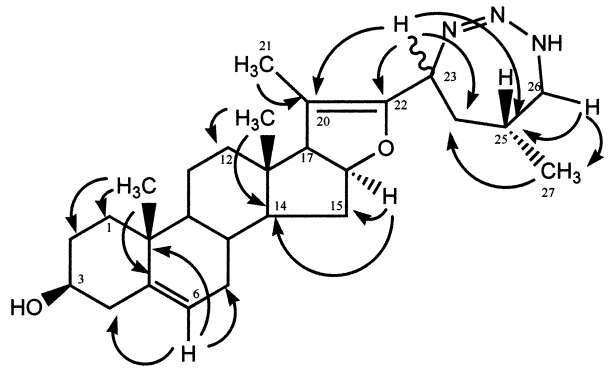

Fig. 3. $\quad{ }^{1} \mathrm{H}-{ }^{13} \mathrm{C}$ Long-Range Correlations Observed for Compound 30

signal due to $\mathrm{H}-23$ at $\delta 4.31(1 \mathrm{H}, \mathrm{t}, J=7.6 \mathrm{~Hz})$, which suggests that the methylene group $\left(\mathrm{CH}_{2}\right)$ at position 23 in 8 changes into a methyne group $(\mathrm{CH})$ in $\mathbf{3 0}$. Two vinyl carbon signals due to C-5 and C- 6 were observed at $\delta 140.8$ and 121.2 , respectively, and two vinyl carbon signals due to $\mathrm{C}-20$ and C-22 of the enol moiety in the E ring were observed at $\delta$ 77.6 and 162.9 in the ${ }^{13} \mathrm{C}$-NMR spectrum, respectively. In the heteronuclear multiple bond connection (HMBC) spectrum of 30 (Fig. 3), correlations between the $\mathrm{H}-23$ signal at $\delta 4.31$ and carbon signals at $\delta 77.6,162.9,29.5$ and 34.2 due to C$20, \mathrm{C}-22, \mathrm{C}-24$ and $\mathrm{C}-25$, respectively, were observed. The configuration at position 23 was not determined in this study. The same reaction of iodide $\mathbf{9}$ with sodium azide as $\mathbf{8}$ under the same reaction conditions (run 19) gave only the azido product (31). Compound 31 was heated at $120^{\circ} \mathrm{C}$ for $20 \mathrm{~h}$ to give 22-((6R)-4,5,6,7-tetrahydro-6-methyl- $1 \mathrm{H}$-1,2,3-triazepin4 -yl)-pseudodiosgenone (32) in $31 \%$ yield. These results suggest that products $\mathbf{3 0}$ and $\mathbf{3 2}$ are obtained via 26 -azido derivatives by the cyclization of the azido group.

The cytotoxicity of synthetic pseudogiosgenin derivatives $2,{ }^{15)} 4,10,12,16-20,26$ and 30 , pseudodiosgenone derivatives $3,{ }^{15)} \mathbf{5}, \mathbf{1 1}, \mathbf{1 3}, \mathbf{2 1}-\mathbf{2 5}$ and $\mathbf{2 7}$, and 5,6-dicyanocholestan-3-one derivatives $\mathbf{1 4}$ and $\mathbf{1 5}$ was evaluated using human colorectal (HCT 116) and human hepatoma (Hep G2) cancer cell lines. The former cells express very little MDR 1 (P-glycoprotein; P-gp),${ }^{19)}$ while the latter cells overexpress Pgp. ${ }^{20)} \mathrm{P}$-gp acts as an efflux pump to remove several antitumor agents, $\mathrm{Ca}^{+}$antagonists, cyclosporine, digoxin and other compounds from cells. ${ }^{21)}$ The cytotoxic activity of each pseudodiosgenin and pseudodiosgonone derivative was estimated by MTT assay, ${ }^{22)}$ and $\mathrm{IC}_{50}$ values calculated based on the percent inhibition of growth are listed in Tables 2 and 3, respectively.

First, the effects on HCT 116 cells of pseudodiosgenins $\mathbf{2}$, 4, 10, 12, 16-20 and 26 (Table 2) were compared with those of pseudodiosgenones $\mathbf{3}, \mathbf{5}, \mathbf{1 1}, \mathbf{1 3}, \mathbf{2 1}-\mathbf{2 5}$ and 27 (Table 3) which had the same side chain structures as the corresponding pseudodiosgenins. Among the pseudodiosgenins, only 2, 4 and 12 showed strong cytotoxic activity $\left(\mathrm{IC}_{50}\right.$ values: $2.6 \pm 0.3-6.7 \pm 1.4 \mu \mathrm{M})$. In contract, the pseudodiosgenones were highly cytotoxic $\left(\mathrm{IC}_{50}\right.$ values: $\left.1.3 \pm 0.3-6.4 \pm 0.3 \mu \mathrm{M}\right)$. Thus, the presence of an $\alpha, \beta$-unsaturated ketone group on the A ring in steroidal compounds may contribute to the cytotoxic activity.

Previously we reported that a comparison of spirostanol derivatives with furostanol derivatives revealed the presence of a cyanoseleno group at position 26 of the furostanol derivative to be important for strong cytotoxic activity. ${ }^{15)}$ The cytotoxicity in HCT 116 cells of 26-cyanohetero compounds
Table 2. Cytotoxic Activities of Pseudodiosgenin Derivatives 2, 4, 10, 12, $16-20,26$ and 30

\begin{tabular}{ccc}
\hline \hline & \multicolumn{2}{c}{$\mathrm{IC}_{50} \pm$ S.D. $(\mu \mathrm{M})^{a)}$} \\
\cline { 2 - 3 } Compound & HCT 116 cells & Hep G2 cells \\
\hline $\mathbf{2}$ & $2.6 \pm 0.3$ & $4.5 \pm 1.5$ \\
$\mathbf{4}$ & $5.3 \pm 0.7$ & $53.5 \pm 5.5$ \\
$\mathbf{1 0}$ & $14.8 \pm 0.7$ & $39.8 \pm 7.4$ \\
$\mathbf{1 2}$ & $6.7 \pm 1.4$ & $1.2 \pm 0.7$ \\
$\mathbf{1 6}$ & $11.6 \pm 1.3$ & $2.2 \pm 0.6$ \\
$\mathbf{1 7}$ & $49.9 \pm 6.8$ & $34.7 \pm 6.9$ \\
$\mathbf{1 8}$ & $13.5 \pm 0.6$ & $6.4 \pm 2.8$ \\
$\mathbf{1 9}$ & $106.9 \pm 5.6$ & $133.1 \pm 27.0$ \\
$\mathbf{2 0}$ & $32.3 \pm 5.1$ & $16.3 \pm 4.1$ \\
$\mathbf{2 6}$ & $16.6 \pm 1.7$ & $8.7 \pm 2.8$ \\
$\mathbf{3 0}$ & $5.4 \pm 0.9$ & $2.1 \pm 0.5$ \\
& & \\
\hline
\end{tabular}

a) $\mathrm{IC}_{50}$ values are the concentrations at which $50 \%$ of the cells are inhibited from growing. S.D., standard deviation. Each experiment was performed in duplicate wells, and drug treatments were performed separately three times.

Table 3. Cytotoxic Activities of Pseudodiosgenone Derivatives 3, 5, 11, 13, 21-25 and 27 and 5,26-Dicyanocholestan-3-one Derivatives 14 and 15

\begin{tabular}{ccc}
\hline \hline & \multicolumn{2}{c}{ IC $_{50} \pm$ S.D. $(\mu \mathrm{M})^{a)}$} \\
\cline { 2 - 3 } Compound & HCT 116 cells & Hep G2 cells \\
\hline $\mathbf{3}$ & $1.7 \pm 0.4$ & $4.9 \pm 1.2$ \\
$\mathbf{5}$ & $1.3 \pm 0.3$ & $3.5 \pm 0.8$ \\
$\mathbf{1 1}$ & $3.7 \pm 0.5$ & $6.0 \pm 0.9$ \\
$\mathbf{1 3}$ & $6.4 \pm 0.3$ & $5.5 \pm 1.4$ \\
$\mathbf{2 1}$ & $3.7 \pm 0.5$ & $2.9 \pm 0.8$ \\
$\mathbf{2 2}$ & $2.8 \pm 0.2$ & $2.4 \pm 0.6$ \\
$\mathbf{2 3}$ & $1.9 \pm 0.3$ & $0.6 \pm 0.1$ \\
$\mathbf{2 4}$ & $3.2 \pm 0.3$ & $3.7 \pm 1.9$ \\
$\mathbf{2 5}$ & $2.6 \pm 0.3$ & $1.6 \pm 0.5$ \\
$\mathbf{2 7}$ & $2.6 \pm 0.4$ & $2.5 \pm 0.3$ \\
$\mathbf{1 4}$ & $5.9 \pm 0.7$ & $12.4 \pm 4.8$ \\
$\mathbf{1 5}$ & $38.6 \pm 6.1$ & $30.4 \pm 6.1$ \\
\hline
\end{tabular}

a) $\mathrm{IC}_{50}$ values are the concentrations at which $50 \%$ of the cells are inhibited from growing. S.D., standard deviation. Each experiment was performed in duplicate wells, and drug treatments were performed separately three times.

was compared with that of 26-cyano compounds. 26Cyanoseleno- 2 and 26-cyanothiopseudodiosgenin 4 were more potent $\left(\mathrm{IC}_{50}\right.$ values: $2.6 \pm 0.3,5.3 \pm 0.7 \mu \mathrm{M}$, respectively) than 26-cyanopseudodiosgenin $12\left(\mathrm{IC}_{50}\right.$ value $\left.6.7 \pm 1.4 \mu \mathrm{M}\right)$. Similarly, 26-cyanoseleno- $\mathbf{3}$ and 26-cyanothiopseudodiosgenone 5 were more potent $\left(\mathrm{IC}_{50}\right.$ values: $1.7 \pm 0.4$, $1.3 \pm 0.3 \mu \mathrm{M}$, respectively) than 26-cyanopseudodiosgenone 13 ( $\mathrm{IC}_{50}$ value: $\left.6.4 \pm 0.3 \mu \mathrm{M}\right)$. These results suggested that the presence of hetero atoms such as selenium and sulfur in the side chain of steroidal compounds enhances the cytotoxicity. However, 25-enepseudodiosgenone $\mathbf{1 1}$ showed strong activity $\left(\mathrm{IC}_{50}\right.$ value: $\left.3.7 \pm 0.5 \mu \mathrm{M}\right)$, though 25 -enepseudodiosgenin $\mathbf{1 0}$ was less active $\left(\mathrm{IC}_{50}\right.$ value: $\left.14.8 \pm 0.7 \mu \mathrm{M}\right)$ than $\mathbf{2}-\mathbf{5}$. Therefore, it seems that the presence of substituents such as $\mathrm{SeCN}$, $\mathrm{SCN}$ and $\mathrm{CN}$ is not essential for enhancement of the cytotoxic activity of steroidal compounds. 5 $\alpha, 26$-Dicyanocholestan-3-one 14 was more potent $\left(\mathrm{IC}_{50}\right.$ value: $\left.5.9 \pm 0.7 \mu \mathrm{M}\right)$ than $5 \beta, 26$-dicyanochorestan-3-one $15(38.6 \pm 6.1 \mu \mathrm{M})$ in HCT 116 cells.

Next, the cytotoxicity on Hep G2 cells of pseudodiosgenins $2,4,10,12,16-20$ and 26 (Table 2) was compared with that of pseudodiosgenones $3,5,11,13,21-25$ and 27 
(Table 3). In spite of the presence of an efflux system such as P-gp, some compounds still showed strong cytotoxic activitiy. In the case of the pseudodiosgenins, although the effect of $2\left(\mathrm{IC}_{50}\right.$ value: $\left.4.5 \pm 1.5 \mu \mathrm{M}\right)$ and $4\left(\mathrm{IC}_{50}\right.$ value: $53.5 \pm 5.5 \mu \mathrm{M})$ on Hep $\mathrm{G} 2$ cells was weaker than that $\left(\mathrm{IC}_{50}\right.$ values: $2.6 \pm 0.3 \mu \mathrm{M}$ for 2 and $5.3 \pm 0.7 \mu \mathrm{M}$ for 4 ) on HCT 116 cells, 2 still exhibited strong activity toward Hep G2 cells. On the other hand, $\mathbf{2 3}$ and $\mathbf{3 0}$ had more of an effect on Hep $\mathrm{G} 2$ cells $\left(\mathrm{IC}_{50}\right.$ values: $0.6 \pm 0.1,2.1 \pm 0.5 \mu \mathrm{M}$, respectively) than HCT 116 cells $(1.9 \pm 0.3,5.4 \pm 0.9 \mu \mathrm{M}$, respectively). Furthermore, pseudodiosgenins 12, 16 and 18 ( $\mathrm{IC}_{50}$ values: $1.2 \pm 0.7,2.2 \pm 0.6,6.4 \pm 2.8 \mu \mathrm{M}$, respectively) and pseudodiosgenones 22, 25 and $27(1.6 \pm 0.5-2.5 \pm 0.3 \mu \mathrm{M})$ had strong effects even on the P-gp-overexpressing Hep G2 cells. Notably, compound $\mathbf{2 3}$ exhibited marked cytotoxic activity $\left(\mathrm{IC}_{50}\right.$ values: $\left.0.6 \pm 0.1 \mu \mathrm{M}\right)$ (Tables 2,3 ).

Previously we reported ${ }^{15)}$ that 26-cyanoselenopseudodiosgenone 3 exhibits efficient antibacterial activity against B. subtilis $168 \mathrm{UV}$ as measured by an image analysis of cell motion. ${ }^{23,24)}$ In this study, antibacterial and antifungal activities of pseudodiosgenins 2, 4, 10, 12, 16-20, 26 and 30, pseudodiosgenones $\mathbf{3}, \mathbf{5}, \mathbf{1 1}, \mathbf{1 3}, \mathbf{2 1}-\mathbf{2 5}$ and 27 , and two 5,26-dicyanocholestan-3-ones $\mathbf{1 4}$ and $\mathbf{1 5}$, were investigated according to the protocols of the national committee for clinical laboratory standards (NCCLS). ${ }^{25-27)}$ Among these compounds, pseudodiosgenones $\mathbf{3}$ and $\mathbf{2 7}$ were effective against gram-positive $B$. subtilis and $S$. aureus (MIC: 7.8$15.6 \mu \mathrm{g} / \mathrm{ml}$ ) (Table 4). Pseudodiosgenones 22 and 25, and pseudodiosgenin 16 were also active against both gram-positive bacteria, although their MIC $(31.3-62.5 \mu \mathrm{g} / \mathrm{ml})$ values were higher than those of the former two compounds. On the other hand, none of the compounds tested revealed any antibacterial activity against gram-negative bacteria $(E$. coli and $P$. aeruginosa). The pseudodiosgenin 16 was the only compound which showed antifungal activity against $C$. albicans (MIC: $62.5 \mu \mathrm{g} / \mathrm{ml})$ and $A$. niger $(62.5 \mu \mathrm{g} / \mathrm{ml})$, though its effects were weak. The other pseudodiosgenins, pseudodiosgenones and 5,26-dicyanocholestan-3-ones used in this study showed no effective antibacterial and antifungal activities; their values were higher than $100 \mu \mathrm{g} / \mathrm{ml}$.

\section{Conclusions}

Reactions of 26-iodopseudodiosgenin 8 and 26-iodopseudodiosgenone 9 with various nucleophiles were performed.

The cytotoxicity of the products were evaluated using HCT 116 and Hep G2 cancer cell lines. Although only four peudodiosgenins, 2, 4, 12 and 30, had strong cytotoxic effects $\left(\mathrm{IC}_{50}\right.$ values: $\left.2.6 \pm 0.3-6.7 \pm 1.4 \mu \mathrm{M}\right)$ on HCT 116 cells, all of the pseudodiosgenones were highly active $\left(\mathrm{IC}_{50}\right.$ values: $1.3 \pm 0.3-6.4 \pm 0.3 \mu \mathrm{M})$ against the same cells. These results suggest that the presence of an $\alpha, \beta$-unsaturated ketone group on the A ring in steroidal compounds contributes to the cytotoxic effect on HCT 116 cells. Against Hep G2 cells overexpress P-gp, pseudodiosgenins 12, 16 and 30 ( $\mathrm{IC}_{50}$ values of $1.2 \pm 0.7,2.2 \pm 0.6,2.1 \pm 0.5 \mu \mathrm{M}$, respectively) and pseudodiosgenones 22, 23, 25 and 27 ( $\mathrm{IC}_{50}$ values of 2.4 \pm 0.6 , $0.6 \pm 0.1,1.6 \pm 0.5,2.5 \pm 0.3 \mu \mathrm{M}$, respectively) showed potent activities. Thus, these compounds were little susceptible to an efflux system such as P-gp in Hep G2 cells. Of all the compounds investigated, 23, 26-(piperidine-1-yl)pseudodiosgenone, had the most potent cytotoxic effect on P-gp-
Table 4. Antibacterial and Antifungal Activities (MIC, $\mu \mathrm{g} / \mathrm{ml}$ ) of Compounds $3,16,22,25$ and $27^{a)}$

\begin{tabular}{ccccc}
\hline \hline Compound & B. subtilis & S. aureus & C. albicans & A. niger \\
\hline $\mathbf{3}$ & 15.6 & 10.4 & $>100^{b)}$ & $>100$ \\
$\mathbf{1 6}$ & 31.3 & 62.5 & 62.5 & 62.5 \\
$\mathbf{2 2}$ & 62.5 & 41.7 & $>100$ & $>100$ \\
$\mathbf{2 5}$ & 31.3 & 31.3 & $>100$ & $>100$ \\
$\mathbf{2 7}$ & 7.8 & 15.6 & $>100$ & $>100$ \\
\hline
\end{tabular}

a) Each experiment was performed in duplicate wells. Drug treatments were performed separately three times. MIC values greater than $100 \mu \mathrm{g} / \mathrm{ml}$ are indicated as $>100$.

overexpressing Hep G2 cells, and also showed marked activity on HCT 116 cells ( $\mathrm{IC}_{50}$ value: $\left.1.9 \pm 0.3 \mu \mathrm{M}\right)$.

The antibacterial and antifungal activity also were investigated. Compounds $\mathbf{3}$ and $\mathbf{2 7}$ were effective against the grampositive bacteria tested, while the other compounds showed little or no activity against these bacteria. Activity against gram-negative bacteria was not observed for all compounds tested. Only compound $\mathbf{1 6}$ showed weak antifungal activity toward $C$. albicans and $A$. niger. The other compounds showed no antifungal activity.

\section{Experimental}

General Methods The chemicals and solvents were of reagent grade and obtained from commercially sources. Melting points $(\mathrm{mp})$ were determined using a Yanagimoto micromelting point apparatus and were uncorrected. Kieselgel $60 \mathrm{~F}_{254}$ (Merck) was utilized for the thin-layer chromatography (TLC). Spots were detected by spraying 1:9 $\mathrm{Ce}\left(\mathrm{SO}_{4}\right)_{2}-10 \% \mathrm{H}_{2} \mathrm{SO}_{4}$ reagent, and heating the plate at $250^{\circ} \mathrm{C}$ for $3 \mathrm{~min}$. Column chromatographies were carried out using a Silica gel 60 (Merck). Then, the eluates were monitored using TLC. An SSC-6300 HPLC instrument (Senshu Scientific Co. Ltd.) was employed for analytical HPLC (DOCOSIL, $10 \times 250 \mathrm{~mm}$; flow rate, $1.0 \mathrm{ml} \mathrm{min}^{-1}$; column temperature $40^{\circ} \mathrm{C}$ ). The SSC-6300 was further equipped with an SSC autoinjector 6310 and an SSC fraction collector 6320 for preparative HPLC (DOCOSIL or DOCOSIL-B, $10 \times 250 \mathrm{~mm}$; flow rate, $1.0 \mathrm{ml} \mathrm{min}{ }^{-1}$; column temperature $40{ }^{\circ} \mathrm{C}$ ). ${ }^{1} \mathrm{H}$ - and ${ }^{13} \mathrm{C}$-NMR spectra at 500 and $125 \mathrm{MHz}$, respectively, as well as ${ }^{1} \mathrm{H}-{ }^{1} \mathrm{H}$ and ${ }^{1} \mathrm{H}-{ }^{13} \mathrm{C}$ COSY, DEPT and HMBC spectra were obtained with a JEOL JNM-A500 FT-NMR spectrometer. Tetramethylsiliane was used as an internal standard. Chemical shifts were given in ppm. Multiplicities of ${ }^{1} \mathrm{H}-\mathrm{NMR}$ signals were indicated as $\mathrm{s}$ (singlet), d (doublet), dd (doublet of doublet), $\mathrm{t}$ (triplet) and $\mathrm{m}$ (multiplet). FAB-MS and high resolution mass (HR-MS) spectra were recorded on a JEOL LMS-DX 300 mass spectrometer.

General Procedure for Preparing 26-Substituted Pseudodiosgenins and 26-Substituted Pseudodiosgenones Reactions of compounds 8 and 9 with various nucleophiles were performed under the conditions listed in Table 1. To a solution of $\mathbf{8}^{15)}$ in DMF $(15 \mathrm{ml})$, was added nuclophile and the reaction mixture was stirred. The reaction mixture was poured into ice-cold water $(50 \mathrm{ml})$ and extracted with dichloromethane $(30 \mathrm{ml} \times 4)$. The extracts were washed with brine, dried over anhydrous sodium sulfate and then filtered. The filtrate was evaporated to give a residue.

26-Cyanothiopseudodiosgenin (4) The reaction of $\mathbf{8}(200 \mathrm{mg}$, $0.38 \mathrm{mmol}$ ) with $\mathrm{KSCN}(148 \mathrm{mg}, 1.52 \mathrm{mmol})$ was performed using standard procedures to obtain a residue. The resulting residue was purified by preparative HPLC $\left(15 \% \mathrm{H}_{2} \mathrm{O}\right.$-acetone) to give 4 ( $70 \mathrm{mg}$ : $40 \%$ yield) as a semisolid. FAB-MS: $m / z$ $478[\mathrm{M}+\mathrm{Na}]^{+}$; FAB-MS $m / z$ : 455.2853 (Calcd for $\mathrm{C}_{28} \mathrm{H}_{41} \mathrm{O}_{2} \mathrm{NS}$ : 455.2858 ); ${ }^{1} \mathrm{H}-\mathrm{NMR}\left(\mathrm{CDCl}_{3}\right)$ (only assignable signals were listed) $\delta: 5.34(1 \mathrm{H}, \mathrm{d}, J=5.5 \mathrm{~Hz}, \mathrm{H}-6), 4.75(1 \mathrm{H}, \mathrm{ddd}, J=10.1,7.9,5.8 \mathrm{~Hz}$, $\mathrm{H}-16), 3.51(1 \mathrm{H}, \mathrm{m}, \mathrm{H}-3), 3.03(1 \mathrm{H}, \mathrm{dd}, J=12.8,5.5 \mathrm{~Hz}, \mathrm{H}-26 \mathrm{a}), 2.80(1 \mathrm{H}$, dd, $J=12.8,7.6 \mathrm{~Hz}, \mathrm{H}-26 \mathrm{~b}), 2.48(1 \mathrm{H}, \mathrm{d}, J=10.1 \mathrm{~Hz}, \mathrm{H}-17), 1.60(3 \mathrm{H}, \mathrm{s}, 21-$ $\left.\mathrm{CH}_{3}\right), 1.07\left(3 \mathrm{H}, \mathrm{d}, J=6.4 \mathrm{~Hz}, 27-\mathrm{CH}_{3}\right), 1.02\left(3 \mathrm{H}, \mathrm{s}, 19-\mathrm{CH}_{3}\right), 0.69(3 \mathrm{H}, \mathrm{s}$, 18- $\left.\mathrm{CH}_{3}\right) ;{ }^{13} \mathrm{C}-\mathrm{NMR}\left(\mathrm{CDCl}_{3}\right) \delta$ : $150.5(\mathrm{C}-22), 140.8(\mathrm{C}-5), 121.2(\mathrm{C}-6)$, 112.7 (SCN), 104.4 (C-20), 84.3 (C-16), 71.5 (C-3), 64.0 (C-17), 54.9 (C14), 50.0 (C-9), 43.2 (C-13), 42.1 (C-4), 41.1 (C-26), 39.4 (C-1), 37.2 (C12), 36.5 (C-10), 34.0 (C-15), 33.2 (C-25), 32.5 (C-24), 32.1 (C-7), 31.5 (C2), 31.1 (C-8), 23.0 (C-11), 20.9 (C-23), 19.3 (C-19), 18.3 (C-27), 13.9 (C18), $11.6(\mathrm{C}-21)$. 
Pseudodiosgenin-25(26)-ene (10) The reaction of 8 (200 $\mathrm{mg}$, $0.38 \mathrm{mmol})$ with $\mathrm{KOCN}(123 \mathrm{mg}, 1.52 \mathrm{mmol})$ was performed using standard procedures to obtain a residue. The resulting residue was purified by preparative $\mathrm{HPLC}\left(15 \% \mathrm{H}_{2} \mathrm{O}\right.$-acetone) to give $\mathbf{1 0}(38 \mathrm{mg}: 25 \%$ yield $)$ as a powder, mp 86-88 ${ }^{\circ} \mathrm{C}$. FAB-MS: $\mathrm{m} / \mathrm{z} 419[\mathrm{M}+\mathrm{Na}]^{+}$; FAB-MS $\mathrm{m} / \mathrm{z}: 396.3022$ (Calcd for $\left.\mathrm{C}_{27} \mathrm{H}_{40} \mathrm{O}_{2}: 396.3029\right) ;{ }^{1} \mathrm{H}-\mathrm{NMR}\left(\mathrm{CDCl}_{3}\right.$ ) (only assignable signals were listed) $\delta: 5.35(1 \mathrm{H}, \mathrm{dt}, J=5.5,2.1 \mathrm{~Hz}, \mathrm{H}-6), 4.74(1 \mathrm{H}, \mathrm{ddd}, J=10.1$, 7.6, $5.8 \mathrm{~Hz}, \mathrm{H}-16), 4.70(2 \mathrm{H}, \mathrm{m}, \mathrm{H}-26), 3.52(1 \mathrm{H}, \mathrm{m}, \mathrm{H}-3), 2.48(1 \mathrm{H}, \mathrm{d}$, $J=10.4 \mathrm{~Hz}, \mathrm{H}-17), 1.73\left(3 \mathrm{H}, \mathrm{s}, 27-\mathrm{CH}_{3}\right), 1.59\left(3 \mathrm{H}, \mathrm{s}, 21-\mathrm{CH}_{3}\right), 1.03(3 \mathrm{H}, \mathrm{s}$, $\left.19-\mathrm{CH}_{3}\right), 0.69\left(3 \mathrm{H}, \mathrm{s}, 18-\mathrm{CH}_{3}\right) ;{ }^{13} \mathrm{C}-\mathrm{NMR}\left(\mathrm{CDCl}_{3}\right) \delta: 151.3(\mathrm{C}-22), 145.4$ (C-25), 140.8 (C-5), 121.4 (C-6), 109.9 (C-26), 103.7 (C-20), 84.3 (C-16), 71.7 (C-3), 64.2 (C-17), 55.0 (C-14), 50.1 (C-9), 43.2 (C-13), 42.2 (C-4), 39.5 (C-1), 37.2 (C-12), 36.6 (C-10), 35.2 (C-24), 34.1 (C-15), 32.2 (C-7), 31.6 (C-2), 31.2 (C-8), 24.4 (C-11), 22.4 (C-27), 21.0 (C-23), 19.4 (C-19), 13.9 (C-18), 11.6 (C-21).

26-Cyanopseudodiosgenin (12) The reaction of $8(200 \mathrm{mg}, 0.32 \mathrm{mmol})$ with $\mathrm{NaCN}(75 \mathrm{mg}, 1.53 \mathrm{mmol})$ was performed using standard procedures to obtain a residue. The resulting residue was subjected to preparative HPLC $\left(15 \% \mathrm{H}_{2} \mathrm{O}\right.$-acetone) to give $\mathbf{1 2}\left(121 \mathrm{mg}: 75 \%\right.$ yield) as a powder, $\mathrm{mp} 132{ }^{\circ} \mathrm{C}$ FAB-MS: $m / z 446 \quad[\mathrm{M}+\mathrm{Na}]^{+}$; FAB-MS $m / z$ : 423.3137 (Calcd for $\mathrm{C}_{28} \mathrm{H}_{41} \mathrm{O}_{2} \mathrm{~N}$ : 423.3137); ${ }^{1} \mathrm{H}-\mathrm{NMR}\left(\mathrm{CDCl}_{3}\right)$ (only assignable signals were listed) $\delta: 5.34(1 \mathrm{H}, \mathrm{d}, J=5.2 \mathrm{~Hz}, \mathrm{H}-6), 4.73(1 \mathrm{H}, \mathrm{ddd}, J=10.1,7.9,5.8 \mathrm{~Hz}$, $\mathrm{H}-16), 3.51(1 \mathrm{H}, \mathrm{m}, \mathrm{H}-3), 2.48(1 \mathrm{H}, \mathrm{d}, J=10.1 \mathrm{~Hz}, \mathrm{H}-17), 2.35(1 \mathrm{H}, \mathrm{dd}$, $J=16.8,5.2 \mathrm{~Hz}, \mathrm{H}-26 \mathrm{a}), 2.24(1 \mathrm{H}, \mathrm{dd}, J=16.7,7.3 \mathrm{~Hz}, \mathrm{H}-26 \mathrm{~b}), 1.59(3 \mathrm{H}, \mathrm{s}$, $\left.21-\mathrm{CH}_{3}\right), 1.08\left(3 \mathrm{H}, \mathrm{d}, J=6.7 \mathrm{~Hz}, 27-\mathrm{CH}_{3}\right), 1.02\left(3 \mathrm{H}, \mathrm{s}, 19-\mathrm{CH}_{3}\right), 0.68(3 \mathrm{H}, \mathrm{s}$, $\left.18-\mathrm{CH}_{3}\right) ;{ }^{13} \mathrm{C}-\mathrm{NMR}\left(\mathrm{CDCl}_{3}\right) \delta: 150.5(\mathrm{C}-22), 140.7(\mathrm{C}-5), 121.2(\mathrm{C}-6)$, $118.7(\mathrm{CN}), 104.2$ (C-20), 84.3 (C-16), 71.4 (C-3), 64.0 (C-17), 54.9 (C-14), 49.9 (C-9), 43.1 (C-13), 42.1 (C-4), 39.4 (C-1), 37.1 (C-12), 36.5 (C-10), 34.0 (C-15), 33.1 (C-24), 32.0 (C-7), 31.4 (C-2), 31.0 (C-8), 29.8 (C-25), 24.2 (C-26), 23.0 (C-11), 20.9 (C-23), 19.3 (C-19), 19.1 (C-27), 13.8 (C-18), $11.5(\mathrm{C}-21)$.

26-Diethylaminopseudodiosgenin (16) The reaction of 8 (200 mg, $0.38 \mathrm{mmol})$ with diethyl amine $(112 \mathrm{mg}, 1.53 \mathrm{mmol})$ was performed using standard procedures to obtain a residue. The resulting residue was subjected to column chromatography (a gradient of $0-90 \%$ acetone in toluene) to give 16 (104 mg: $58 \%$ yield) as a powder, mp $115-117^{\circ} \mathrm{C}$. FAB-MS: $\mathrm{m} / \mathrm{z}$ $492[\mathrm{M}+\mathrm{Na}]^{+}$; FAB-MS m/z: 470.3992 (Calcd for $\mathrm{C}_{31} \mathrm{H}_{51} \mathrm{O}_{2} \mathrm{~N}+\mathrm{H}$ : 470.3998); ${ }^{1} \mathrm{H}-\mathrm{NMR}\left(\mathrm{CDCl}_{3}\right.$ ) (only assignable signals were listed) $\delta: 5.34$ $(1 \mathrm{H}, \mathrm{d}, J=5.2 \mathrm{~Hz}, \mathrm{H}-6), 4.72(1 \mathrm{H}, \mathrm{ddd}, J=10.1,7.9,5.8 \mathrm{~Hz}, \mathrm{H}-16), 3.51$ $(1 \mathrm{H}, \mathrm{m}, \mathrm{H}-3), 2.47\left(4 \mathrm{H}, \mathrm{CH}_{2} \times 2, \mathrm{q}, J=7.0 \mathrm{~Hz}, \mathrm{NCH}_{2} \mathrm{CH}_{3}\right), 2.46(1 \mathrm{H}, \mathrm{d}$, $J=10.4 \mathrm{~Hz}, \mathrm{H}-17), 2.23(1 \mathrm{H}, \mathrm{dd}, J=12.5,5.8 \mathrm{~Hz}, \mathrm{H}-26 \mathrm{a}), 2.09(1 \mathrm{H}, \mathrm{dd}$, $J=12.5,7.6 \mathrm{~Hz}, \mathrm{H}-26 \mathrm{~b}), 1.59\left(3 \mathrm{H}, \mathrm{s}, 21-\mathrm{CH}_{3}\right), 1.02\left(3 \mathrm{H}, \mathrm{s}, 19-\mathrm{CH}_{3}\right), 0.98$ $\left(6 \mathrm{H}, \mathrm{CH}_{3} \times 2, \mathrm{t}, J=7.0 \mathrm{~Hz}, \mathrm{NCH}_{2} \mathrm{CH}_{3}\right), 0.90\left(3 \mathrm{H}, \mathrm{d}, J=6.4 \mathrm{~Hz}, 27-\mathrm{CH}_{3}\right), 0.69$ $\left(3 \mathrm{H}, \mathrm{s}, 18-\mathrm{CH}_{3}\right) ;{ }^{13} \mathrm{C}-\mathrm{NMR}\left(\mathrm{CDCl}_{3}\right) \delta: 152.0(\mathrm{C}-22), 140.8(\mathrm{C}-5), 121.2(\mathrm{C}-$ 6), 103.2 (C-20), 84.1 (C-16), 71.4 (C-3), 64.1 (C-17), 60.1 (C-26), 55.0 (C14), 50.0 (C-9), $47.4\left(\mathrm{NCH}_{2} \mathrm{CH}_{3}\right), 43.2$ (C-13), 42.2 (C-4), 39.5 (C-1), 37.2 (C-12), 36.5 (C-10), 34.1 (C-15), 32.7 (C-24), 32.1 (C-7), 31.5 (C-2), 31.2 (C-8), 31.1 (C-25), 23.4 (C-11), 20.9 (C-23), 19.3 (C-19), 18.3 (C-27), 13.8 (C-18), $11.6\left(\mathrm{C}-21\right.$ and $\left.\mathrm{NCH}_{2} \mathrm{CH}_{3}\right)$.

26-(Pyrrolidin-1-yl)pseudodiosgenin (17) The reaction of 8 (200 mg, $0.38 \mathrm{mmol}$ ) with pyrrolidine ( $108 \mathrm{mg}, 1.52 \mathrm{mmol}$ ) was performed using standard procedures to obtain a residue. Compound 17 was crystallized from an acetone solution of the residue. The recrystallization from acetone gave $\mathbf{1 7}$ (125 mg: $70 \%$ yield) as needles, $\mathrm{mp} 181-183^{\circ} \mathrm{C}$. FAB-MS: $\mathrm{m} / \mathrm{z} 468$ $[\mathrm{M}+\mathrm{H}]^{+}$; FAB-MS $\mathrm{m} / \mathrm{z}$ : 468.3836 (Calcd for $\mathrm{C}_{31} \mathrm{H}_{49} \mathrm{O}_{2} \mathrm{~N}+\mathrm{H}: 468.3842$ ); ${ }^{1} \mathrm{H}-\mathrm{NMR}\left(\mathrm{CDCl}_{3}\right)$ (only assignable signals were listed) $\delta: 5.35(1 \mathrm{H}, \mathrm{d}$, $J=5.2 \mathrm{~Hz}, \mathrm{H}-6), 4.73(1 \mathrm{H}, \mathrm{ddd}, J=10.1,7.9,5.8 \mathrm{~Hz}, \mathrm{H}-16), 3.51(1 \mathrm{H}, \mathrm{m}, \mathrm{H}-$ 3), $2.46(1 \mathrm{H}, \mathrm{d}, J=10.1 \mathrm{~Hz}, \mathrm{H}-17), 2.43(2 \mathrm{H} \times 2, \mathrm{~m}$, pyrrolidine- 2$), 2.25(2 \mathrm{H}$, d, $J=6.7 \mathrm{~Hz}, \mathrm{H}-26), 1.75\left(2 \mathrm{H} \times 2, \mathrm{~m}\right.$, pyrrolidine-3), $1.59\left(3 \mathrm{H}, \mathrm{s}, 21-\mathrm{CH}_{3}\right)$, $1.02\left(3 \mathrm{H}, \mathrm{s}, 19-\mathrm{CH}_{3}\right), 0.93\left(3 \mathrm{H}, \mathrm{d}, J=6.7 \mathrm{~Hz}, 27-\mathrm{CH}_{3}\right), 0.69\left(3 \mathrm{H}, \mathrm{s}, 18-\mathrm{CH}_{3}\right)$; ${ }^{13} \mathrm{C}-\mathrm{NMR}\left(\mathrm{CDCl}_{3}\right) \delta: 152.0(\mathrm{C}-22), 140.8(\mathrm{C}-5), 121.3(\mathrm{C}-6), 103.3(\mathrm{C}-20)$, 84.2 (C-16), 71.5 (C-3), 64.2 (C-17), 63.6 (C-26), 55.0 (C-14), 54.4 (pyrrolidine), 50.1 (C-9), 43.2 (C-13), 42.2 (C-4), 39.5 (C-1), 37.2 (C-12), 36.6 (C10), 34.1 (C-15), 32.8 (C-24), 32.1 (C-7), 32.0 (C-25), 31.6 (C-2), 31.2 (C8), 23.4 (C-11, pyrrolidine), 21.0 (C-23), 19.4 (C-19), 18.3 (C-27), 13.9 (C18), $11.6(\mathrm{C}-21)$.

26-(Piperidin-1-yl)pseudodiosgenin (18) The reaction of 8 (200 $\mathrm{mg}$, $0.38 \mathrm{mmol})$ with piperidine $(130 \mathrm{mg}, 1.52 \mathrm{mmol})$ was performed using standard procedures to obtain a residue. The resulting residue was subjected to column chromatography (a gradient of $0-90 \%$ acetone in toluene) to give 18 (148 mg: $80 \%$ yield) as a powder, $\mathrm{mp} 170-172{ }^{\circ} \mathrm{C}$. FAB-MS: $\mathrm{m} / \mathrm{z} 504$ $[\mathrm{M}+\mathrm{Na}]^{+}$; FAB-MS $m / z$ : 482.4003 (Calcd for $\mathrm{C}_{32} \mathrm{H}_{51} \mathrm{O}_{2} \mathrm{~N}+\mathrm{H}$ : 482.3998); ${ }^{1} \mathrm{H}-\mathrm{NMR}\left(\mathrm{CDCl}_{3}\right)$ (only assignable signals were listed) $\delta: 5.34(1 \mathrm{H}, \mathrm{d}$, $J=5.2 \mathrm{~Hz}, \mathrm{H}-6), 4.72(1 \mathrm{H}, \mathrm{ddd}, J=10.1,7.6,5.5 \mathrm{~Hz}, \mathrm{H}-16), 3.51(1 \mathrm{H}, \mathrm{m}, \mathrm{H}-$
3), $2.46(1 \mathrm{H}, \mathrm{d}, J=10.1 \mathrm{~Hz}, \mathrm{H}-17), 2.28(2 \mathrm{H} \times 2, \mathrm{~m}$, piperidine-2), $2.11(1 \mathrm{H}$, dd, $J=12.2,6.4 \mathrm{~Hz}, \mathrm{H}-26 \mathrm{a}), 2.02(1 \mathrm{H}, \mathrm{dd}, J=12.2,7.9 \mathrm{~Hz}, \mathrm{H}-26 \mathrm{~b}), 1.59(3 \mathrm{H}$, $\left.\mathrm{s}, 21-\mathrm{CH}_{3}\right), 1.54(2 \mathrm{H} \times 2, \mathrm{~m}$, piperidine- 3$), 1.41(2 \mathrm{H}, \mathrm{m}$, piperidine- 4$), 1.02$ $\left(3 \mathrm{H}, \mathrm{s}, 19-\mathrm{CH}_{3}\right), 0.89\left(3 \mathrm{H}, \mathrm{d}, J=6.4 \mathrm{~Hz}, 27-\mathrm{CH}_{3}\right), 0.69\left(3 \mathrm{H}, \mathrm{s}, 18-\mathrm{CH}_{3}\right) ;{ }^{13} \mathrm{C}-$ NMR $\left(\mathrm{CDCl}_{3}\right) \delta: 152.0(\mathrm{C}-22), 140.8(\mathrm{C}-5), 121.2(\mathrm{C}-6), 103.3(\mathrm{C}-20), 84.2$ (C-16), 71.5 (C-3), 66.2 (C-26), 64.2 (C-17), 55.0 (C-14, piperidine), 50.0 (C-9), 43.2 (C-13), 42.2 (C-4), 39.5 (C-1), 37.2 (C-12), 36.6 (C-10), 34.1 (C-15), 32.8 (C-24), 32.1 (C-7), 31.5 (C-2), 31.2 (C-8), 29.8 (C-25), 25.9 (piperidine), 24.5 (piperidine), 23.3 (C-11), 21.0 (C-23), 19.4 (C-19), 18.3 (C-27), 13.9 (C-18), 11.6 (C-21).

26-Morpholinopseudodiosgenin (19) The reaction of 8 (200 $\mathrm{mg}$, $0.32 \mathrm{mmol}$ ) with morpholine $(132 \mathrm{mg}, 1.52 \mathrm{mmol}$ ) was performed using standard procedures to obtain a residue. The resulting residue was purified by recrystallization from acetone to give 19 (100 mg: $54 \%$ yield) as a powder, mp $185-187^{\circ} \mathrm{C}$. FAB-MS: $m / z 484[\mathrm{M}+\mathrm{H}]^{+}$; FAB-MS $m / z$ : 484.3787 (Calcd for $\mathrm{C}_{31} \mathrm{H}_{49} \mathrm{O}_{3} \mathrm{~N}+\mathrm{H}$ : 484.3791); ${ }^{1} \mathrm{H}-\mathrm{NMR}\left(\mathrm{CDCl}_{3}\right)$ (only assignable signals were listed) $\delta: 5.34(1 \mathrm{H}, \mathrm{d}, J=5.2 \mathrm{~Hz}, \mathrm{H}-6), 4.72(1 \mathrm{H}, \mathrm{ddd}, J=10.1$, $7.9,5.8 \mathrm{~Hz}, \mathrm{H}-16), 3.67(2 \mathrm{H} \times 2$, td, $J=4.9,1.5 \mathrm{~Hz}$, morpholine-2), $3.51(1 \mathrm{H}$, $\mathrm{m}, \mathrm{H}-3), 2.47(1 \mathrm{H}, \mathrm{d}, J=10.1 \mathrm{~Hz}, \mathrm{H}-17), 2.37(2 \mathrm{H} \times 2, \mathrm{~m}$, morpholine-3), $2.15(1 \mathrm{H}, \mathrm{dd}, J=12.2,6.7 \mathrm{~Hz}, \mathrm{H}-26 \mathrm{a}), 2.07(1 \mathrm{H}, \mathrm{dd}, J=12.2,7.6 \mathrm{~Hz}, \mathrm{H}-26 \mathrm{~b})$, $1.59\left(3 \mathrm{H}, \mathrm{s}, 21-\mathrm{CH}_{3}\right), 1.02\left(3 \mathrm{H}, \mathrm{s}, 19-\mathrm{CH}_{3}\right), 0.91\left(3 \mathrm{H}, \mathrm{d}, J=6.7 \mathrm{~Hz}, 27-\mathrm{CH}_{3}\right)$, $0.69\left(3 \mathrm{H}, \mathrm{s}, 18-\mathrm{CH}_{3}\right) ;{ }^{13} \mathrm{C}-\mathrm{NMR}\left(\mathrm{CDCl}_{3}\right) \delta: 151.9(\mathrm{C}-22), 140.9(\mathrm{C}-5)$, 121.3 (C-6), 103.5 (C-20), 84.2 (C-16), 71.6 (C-3), 67.0 (morpholine), 65.8 (C-26), 64.2 (C-17), 55.0 (C-14), 54.0 (morpholine), 50.1 (C-9), 43.2 (C13), 42.3 (C-4), 39.5 (C-1), 37.3 (C-12), 36.6 (C-10), 34.1 (C-15), 32.5 (C24), 32.2 (C-7), 31.6 (C-2), 31.2 (C-8), 29.4 (C-25), 23.2 (C-11), 21.0 (C23), 19.4 (C-19), 18.1 (C-27), 13.9 (C-18), 11.7 (C-21).

26-(4-Methylpiperazin-1-yl)pseudodiosgenin (20) The reaction of 8 ( $200 \mathrm{mg}, 0.32 \mathrm{mmol})$ with 1-methylpiperadine $(152 \mathrm{mg}, 1.52 \mathrm{mmol})$ was performed using standard procedures to obtain a residue. The resulting residue was purified by recrystallization from acetone to give $20(117 \mathrm{mg}$ : $62 \%$ yield) as a powder, mp $207-209^{\circ} \mathrm{C}$. FAB-MS: $m / z 497[\mathrm{M}+\mathrm{H}]^{+}$; FAB-MS $m / z$ : 497.4106 (Calcd for $\left.\mathrm{C}_{32} \mathrm{H}_{52} \mathrm{O}_{2} \mathrm{~N}_{2}+\mathrm{H}: 497.4107\right)$; ${ }^{1} \mathrm{H}-\mathrm{NMR}\left(\mathrm{CDCl}_{3}\right)$ (only assignable signals were listed) $\delta: 5.34(1 \mathrm{H}, \mathrm{d}, J=5.2 \mathrm{~Hz}, \mathrm{H}-6), 4.72$ $(1 \mathrm{H}, \mathrm{ddd}, J=10.1,7.9,5.8 \mathrm{~Hz}, \mathrm{H}-16), 3.51(1 \mathrm{H}, \mathrm{m}, \mathrm{H}-3), 2.46(1 \mathrm{H}, \mathrm{d}$, $J=10.1 \mathrm{~Hz}, \mathrm{H}-17), 2.41(2 \mathrm{H} \times 4, \mathrm{~m}$, piperazine $), 2.27\left(3 \mathrm{H}, \mathrm{s}, \mathrm{N}-\mathrm{CH}_{3}\right), 2.17$ $(1 \mathrm{H}, \mathrm{dd}, J=12.2,6.4 \mathrm{~Hz}, \mathrm{H}-26 \mathrm{a}), 2.07$ (1H, dd, $J=12.2,7.9 \mathrm{~Hz}, \mathrm{H}-26 \mathrm{~b}), 1.59$ $\left(3 \mathrm{H}, \mathrm{s}, 21-\mathrm{CH}_{3}\right), 1.02\left(3 \mathrm{H}, \mathrm{s}, 19-\mathrm{CH}_{3}\right), 0.89\left(3 \mathrm{H}, \mathrm{d}, J=6.4 \mathrm{~Hz}, 27-\mathrm{CH}_{3}\right), 0.69$ $\left(3 \mathrm{H}, \mathrm{s}, 18-\mathrm{CH}_{3}\right) ;{ }^{13} \mathrm{C}-\mathrm{NMR}\left(\mathrm{CDCl}_{3}\right) \delta: 151.9(\mathrm{C}-22), 141.0(\mathrm{C}-5), 121.2(\mathrm{C}-$ 6), 103.5 (C-20), 84.2 (C-16), 71.4 (C-3), 65.3 (C-26), 64.2 (C-17), 55.1 (piperazine), 55.0 (C-14), 53.4 (piperazine), $50.1(\mathrm{C}-9), 46.0\left(\mathrm{~N}^{-} \mathrm{CH}_{3}\right), 43.2$ (C-13), 42.3 (C-4), 39.5 (C-1), 37.3 (C-12), 36.6 (C-10), 34.1 (C-15), 32.6 (C-24), 32.2 (C-7), 31.6 (C-2), 31.2 (C-8), 29.7 (C-25), 23.3 (C-11), 21.0 (C-23), 19.4 (C-19), 18.2 (C-27), 13.9 (C-18), 11.7 (C-21).

26-(1H-Imidazol-1-yl)pseudodiosgenin (26) The reaction of 8 $(200 \mathrm{mg}, 0.38 \mathrm{mmol})$ with imidazole $(104 \mathrm{mg}, 1.52 \mathrm{mmol})$ and $\mathrm{K}_{2} \mathrm{CO}_{3}$ $(525 \mathrm{mg}, 3.8 \mathrm{mmol})$ was performed using standard procedures to obtain a residue. The resulting residue was subjected to column chromatography (a gradient of $0-100 \%$ acetone in toluene) to give $\mathbf{2 6}$ (59 $\mathrm{mg}: 33 \%$ yield) and 10 (71 mg: $47 \%$ yield). Compound 26 was a powder, $\mathrm{mp} 181-184^{\circ} \mathrm{C}$. FABMS: $m / z 465[\mathrm{M}+\mathrm{H}]^{+}$; FAB-MS $m / z$ : $465.3470\left(\right.$ Calcd for $\mathrm{C}_{30} \mathrm{H}_{44} \mathrm{O}_{2} \mathrm{~N}_{2}+\mathrm{H}$ : 465.3481); ${ }^{1} \mathrm{H}$-NMR $\left(\mathrm{CDCl}_{3}\right.$ ) (only assignable signals were listed) $\delta: 7.43$ (1H, s, imidazole-2), $7.04(1 \mathrm{H}, \mathrm{s}$, imidazole-4), $6.87(1 \mathrm{H}, \mathrm{s}$, imidazole-5), $5.34(1 \mathrm{H}, \mathrm{d}, J=5.5 \mathrm{~Hz}, \mathrm{H}-6), 4.73$ (1H, ddd, $J=10.1,8.1,5.5 \mathrm{~Hz}, \mathrm{H}-16), 3.52$ $(1 \mathrm{H}, \mathrm{m}, \mathrm{H}-3), 3.89(1 \mathrm{H}, \mathrm{dd}, J=13.7,5.8 \mathrm{~Hz}, \mathrm{H}-26 \mathrm{a}), 3.67(1 \mathrm{H}, \mathrm{dd}, J=13.7$, $7.9 \mathrm{~Hz}, \mathrm{H}-26 \mathrm{~b}), 2.47(1 \mathrm{H}, \mathrm{d}, J=10.1 \mathrm{~Hz}, \mathrm{H}-17), 1.58\left(3 \mathrm{H}, \mathrm{s}, 21-\mathrm{CH}_{3}\right), 1.02$ $\left(3 \mathrm{H}, \mathrm{s}, 19-\mathrm{CH}_{3}\right), 0.87\left(3 \mathrm{H}, \mathrm{d}, J=6.7 \mathrm{~Hz}, 27-\mathrm{CH}_{3}\right), 0.68\left(3 \mathrm{H}, \mathrm{s}, 18-\mathrm{CH}_{3}\right) ;{ }^{13} \mathrm{C}-$ NMR $\left(\mathrm{CDCl}_{3}\right) \delta: 150.8$ (C-22), 141.0 (C-5), 137.3 (imidazole), 128.9 (imidazole), 121.0 (C-6), 119.3 (imidazole), 104.2 (C-20), 84.3 (C-16), 71.3 (C3), 64.0 (C-17), 54.9 (C-14), 53.1 (C-26), 50.0 (C-9), 43.2 (C-13), 42.2 (C4), 39.4 (C-1), 37.2 (C-12), 36.5 (C-10), 34.3 (C-25), 34.0 (C-15), 32.2 (C7), 31.5 (C-2), 31.4 (C-24), 31.2 (C-8), 23.0 (C-11), 20.9 (C-23), 19.3 (C19), 17.2 (C-27), 13.9 (C-18), 11.6 (C-21).

22-((6R)-4,5,6,7-Tetrahydro-6-methyl-1H-1,2,3-triazepin-4-yl)pseudodiosgenin (30) The reaction of $\mathbf{8}(200 \mathrm{mg}, 0.38 \mathrm{mmol})$ with $\mathrm{NaN}_{3}(99 \mathrm{mg}$, $1.52 \mathrm{mmol}$ ) was performed using standard procedures to obtain a residue. The resulting residue was subjected to column chromatography (a gradient of $0-30 \%$ ethyl acetate in toluene) to give $30(50 \mathrm{mg}: 43 \%$ yield) as a foam. FAB-MS: $m / z \quad 440 \quad[\mathrm{M}+\mathrm{H}]^{+}$; FAB-MS $m / z$ : 440.3255 (Calcd for $\left.\mathrm{C}_{27} \mathrm{H}_{41} \mathrm{O}_{2} \mathrm{~N}_{3}+\mathrm{H}: 440.3277\right) ;{ }^{1} \mathrm{H}-\mathrm{NMR}\left(\mathrm{CDCl}_{3}\right)$ (only assignable signals were listed) $\delta: 5.30(1 \mathrm{H}, \mathrm{d}, J=5.2 \mathrm{~Hz}, \mathrm{H}-6), 4.93(1 \mathrm{H}, \mathrm{ddd}, J=7.6,6.4,3.7 \mathrm{~Hz}, \mathrm{H}-$ 16), $4.31(1 \mathrm{H}, \mathrm{t}, J=7.6 \mathrm{~Hz}, \mathrm{H}-23), 3.52(1 \mathrm{H}, \mathrm{m}, \mathrm{H}-3), 3.25(1 \mathrm{H}, \mathrm{dd}, J=11.9$, $5.8 \mathrm{~Hz}, \mathrm{H}-26 \mathrm{a}), 2.09$ ( $1 \mathrm{H}, \mathrm{dd}, J=11.9,7.0 \mathrm{~Hz}, \mathrm{H}-26 \mathrm{~b}), 2.03(2 \mathrm{H}, \mathrm{td}, J=7.6$, $1.2 \mathrm{~Hz}, \mathrm{H}-24), 2.00(1 \mathrm{H}, \mathrm{d}, J=6.4 \mathrm{~Hz}, \mathrm{H}-17), 1.79(1 \mathrm{H}, \mathrm{m}, \mathrm{H}-25), 1.54(3 \mathrm{H}$, 
s, 21- $\left.\mathrm{CH}_{3}\right), 1.02\left(3 \mathrm{H}, \mathrm{s}, 19-\mathrm{CH}_{3}\right), 0.96\left(3 \mathrm{H}, \mathrm{d}, J=6.4 \mathrm{~Hz}, 27-\mathrm{CH}_{3}\right), 0.82(3 \mathrm{H}$, s, $\left.18-\mathrm{CH}_{3}\right) ;{ }^{13} \mathrm{C}-\mathrm{NMR}\left(\mathrm{CDCl}_{3}\right) \delta: 162.9(\mathrm{C}-22), 140.8(\mathrm{C}-5), 121.2(\mathrm{C}-6)$, 91.2 (C-23), 84.2 (C-16), 77.6 (C-20), 71.6 (C-3), 66.2 (C-17), 57.4 (C-26), 56.8 (C-14), 49.8 (C-9), 42.2 (C-4), 40.2 (C-13), 39.0 (C-12), 37.2 (C-1), 36.5 (C-10), 34.2 (C-25), 33.1 (C-15), 31.8 (C-7), 31.6 (C-2), 30.9 (C-8), 29.5 (C-24), 21.2 (C-21), 20.3 (C-11), 19.4 (C-19), 17.7 (C-27), 13.2 (C-18).

26-Cyanothiopseudodiosgenone (5) The reaction of $9(200 \mathrm{mg}$, $0.38 \mathrm{mmol})$ with $\mathrm{KSCN}(148 \mathrm{mg}, 1.52 \mathrm{mmol})$ was performed using standard procedures to obtain a residue. The resulting residue was subjected to preparative HPLC $\left(15 \% \mathrm{H}_{2} \mathrm{O}\right.$-acetone) to give $\mathbf{5}(137 \mathrm{mg}$ : $79 \%$ yield) as a semisolid. FAB-MS: $m / z 476[\mathrm{M}+\mathrm{Na}]^{+}$; FAB-MS $m / z$ : 454.2754 (Calcd for $\mathrm{C}_{28} \mathrm{H}_{39} \mathrm{O}_{2} \mathrm{NS}+\mathrm{H}: 454.2780$ ); ${ }^{1} \mathrm{H}-\mathrm{NMR}\left(\mathrm{CDCl}_{3}\right)$ (only assignable signals were listed) $\delta: 5.72(1 \mathrm{H}, \mathrm{s}, \mathrm{H}-4), 4.75(1 \mathrm{H}, \mathrm{ddd}, J=10.1,7.9,5.5 \mathrm{~Hz}, \mathrm{H}-16)$, $3.03(1 \mathrm{H}, \mathrm{dd}, J=12.8,5.5 \mathrm{~Hz}, \mathrm{H}-26 \mathrm{a}), 2.81(1 \mathrm{H}, \mathrm{dd}, J=12.8,7.6 \mathrm{~Hz}, \mathrm{H}-26 \mathrm{~b})$, $2.48(1 \mathrm{H}, \mathrm{d}, J=10.1 \mathrm{~Hz}, \mathrm{H}-17), 1.60\left(3 \mathrm{H}, \mathrm{s}, 21-\mathrm{CH}_{3}\right), 1.20\left(3 \mathrm{H}, \mathrm{s}, 19-\mathrm{CH}_{3}\right)$, $1.08\left(3 \mathrm{H}, \mathrm{d}, J=6.4 \mathrm{~Hz}, 27-\mathrm{CH}_{3}\right), 0.72\left(3 \mathrm{H}, \mathrm{s}, 18-\mathrm{CH}_{3}\right) ;{ }^{13} \mathrm{C}-\mathrm{NMR}\left(\mathrm{CDCl}_{3}\right) \delta$ : 199.3 (C-3), 170.9 (C-5), 150.8 (C-22), 123.8 (C-4), 112.7 (SCN), 104.2 (C20), 84.1 (C-16), 64.0 (C-17), 54.1 (C-14), 53.6 (C-9), 43.3 (C-13), 41.2 (C26), 39.2 (C-12), 38.6 (C-10), 35.6 (C-1), 34.9 (C-8), 33.9 (C-2), 33.2 (C25), 32.7 (C-6), 32.5 (C-24), 32.2 (C-7 and C-15), 23.0 (C-11), 20.9 (C-23), 18.3 (C-27), 17.3 (C-19), 14.0 (C-18), 11.6 (C-21).

Pseudodiosgenon-25(26)-ene (11) The reaction of 9 (200 $\mathrm{mg}$, $0.38 \mathrm{mmol}$ ) with $\mathrm{KOCN}(62 \mathrm{mg}, 0.76 \mathrm{mmol})$ was performed using standard procedures to obtain a residue. The resulting residue was subjected to preparative $\mathrm{HPLC}\left(15 \% \mathrm{H}_{2} \mathrm{O}\right.$-acetone) to give $\mathbf{1 1}$ (61 mg: $40 \%$ yield) as a semisolid. FAB-MS: $m / z 417$ [M+Na] $]^{+}$; FAB-MS $m / z: 395.2939$ (Calcd for $\mathrm{C}_{27} \mathrm{H}_{38} \mathrm{O}_{2}+\mathrm{H}: 395.2951$ ); ${ }^{1} \mathrm{H}-\mathrm{NMR}\left(\mathrm{CDCl}_{3}\right)$ (only assignable signals were listed) $\delta: 5.73(1 \mathrm{H}, \mathrm{s}, \mathrm{H}-4), 4.74(1 \mathrm{H}, \mathrm{ddd}, J=10.4,8.2,5.8 \mathrm{~Hz}, \mathrm{H}-16), 4.70$ $(2 \mathrm{H}, \mathrm{m}, \mathrm{H}-26), 2.48(1 \mathrm{H}, \mathrm{d}, J=10.4 \mathrm{~Hz}, \mathrm{H}-17), 1.73\left(3 \mathrm{H}, \mathrm{s}, 27-\mathrm{CH}_{3}\right), 1.59$ $\left(3 \mathrm{H}, \mathrm{s}, 21-\mathrm{CH}_{3}\right), 1.20\left(3 \mathrm{H}, \mathrm{s}, 19-\mathrm{CH}_{3}\right), 0.72\left(3 \mathrm{H}, \mathrm{s}, 18-\mathrm{CH}_{3}\right) ;{ }^{13} \mathrm{C}-\mathrm{NMR}$ $\left(\mathrm{CDCl}_{3}\right) \delta: 199.3(\mathrm{C}-3), 171.0(\mathrm{C}-5), 151.5(\mathrm{C}-22), 145.2(\mathrm{C}-25), 123.8(\mathrm{C}-$ 4), 110.0 (C-26), 103.5 (C-20), 84.0 (C-16), 64.1 (C-17), 54.1 (C-14), 53.7 (C-9), 43.2 (C-13), 39.3 (C-12), 38.6 (C-10), 35.6 (C-1), 35.1 (C-15), 34.9 (C-8), 33.9 (C-2 and C-24), 32.7 (C-6), 32.2 (C-7), 24.3 (C-11), 22.3 (C-27), 20.9 (C-23), 17.3 (C-19), 14.0 (C-18), 11.5 (C-21).

$5 \alpha, 26-D i c y a n o c o l e s t a n-3-0 n e(14)$ and $5 \beta, 26$-Dicyanocolestan-3-one (15) from 9 The reaction of $9(200 \mathrm{mg}, 0.38 \mathrm{mmol})$ with $\mathrm{NaCN}(75 \mathrm{mg}$, $1.53 \mathrm{mmol}$ ) was performed for $12 \mathrm{~h}$ as described to obtain a residue. The resulting residue was subjected to preparative $\mathrm{HPLC}\left(37.5 \% \mathrm{H}_{2} \mathrm{O}\right.$-acetone) to give 14 (31 mg: $18 \%$ ) and 15 (31 mg: 18\%). FAB-MS of 14: $\mathrm{m} / \mathrm{z} 471$ $[\mathrm{M}+\mathrm{Na}]^{+}$; FAB-MS m/z: 448.3087 (Calcd for $\mathrm{C}_{29} \mathrm{H}_{40} \mathrm{O}_{2} \mathrm{~N}_{2}: 448.3090$ ); ${ }^{1} \mathrm{H}-$ NMR $\left(\mathrm{CDCl}_{3}\right)$ (only assignable signals were listed) $\delta: 4.75(1 \mathrm{H}$, ddd, $J=10.4,7.9,5.8 \mathrm{~Hz}, \mathrm{H}-16), 2.54(1 \mathrm{H}, \mathrm{d}, J=15.9 \mathrm{~Hz}, \mathrm{H}-4 \mathrm{a}), 2.51(1 \mathrm{H}, \mathrm{d}$, $J=10.4 \mathrm{~Hz}, \mathrm{H}-17), 2.47(1 \mathrm{H}, \mathrm{d}, J=15.9 \mathrm{~Hz}, \mathrm{H}-4 \mathrm{~b}), 2.35(1 \mathrm{H}, \mathrm{dd}, J=16.8$ $5.50 \mathrm{~Hz}, \mathrm{H}-26 \mathrm{a}), 2.24(1 \mathrm{H}, \mathrm{dd}, J=16.8,7.3 \mathrm{~Hz}, \mathrm{H}-26 \mathrm{~b}), 1.59(3 \mathrm{H}, \mathrm{s}, 21-$ $\left.\mathrm{CH}_{3}\right), 1.15\left(3 \mathrm{H}, \mathrm{s}, 19-\mathrm{CH}_{3}\right), 1.09\left(3 \mathrm{H}, \mathrm{d}, J=6.7 \mathrm{~Hz}, 27-\mathrm{CH}_{3}\right), 0.69(3 \mathrm{H}, \mathrm{s}$, $\left.18-\mathrm{CH}_{3}\right) ;{ }^{13} \mathrm{C}-\mathrm{NMR}\left(\mathrm{CDCl}_{3}\right) \delta: 206.1(\mathrm{C}-3), 150.9(\mathrm{C}-22), 122.1(5-\mathrm{CN})$, 118.8 (26-CN), 104.2 (C-20), 84.2 (C-16), 64.0 (C-17), 53.9 (C-14), 49.3 (C-9), 47.3 (C-5), 47.2 (C-4), 43.5 (C-13), 39.1 (C-12), 37.9 (C-10), 37.1 (C-1), 34.2 (C-6 and C-8), 33.8 (C-2), 33.2 (C-24), 31.4 (C-15), 29.9 (C-25), 28.3 (C-7), 24.3 (C-26), 23.1 (C-11), 21.4 (C-23), 19.3 (C-27), 14.2 (C-18), 12.1 (C-19), $11.6(\mathrm{C}-21)$. FAB-MS of 15: $\mathrm{m} / \mathrm{z} 471[\mathrm{M}+\mathrm{Na}]^{+}$; FAB-MS $\mathrm{m} / \mathrm{z}$ : 448.3085 (Calcd for $\mathrm{C}_{29} \mathrm{H}_{40} \mathrm{O}_{2} \mathrm{~N}_{2}: 448.3090$ ); ${ }^{1} \mathrm{H}-\mathrm{NMR}\left(\mathrm{CDCl}_{3}\right.$ ) (only assignable signals were listed) $\delta: 4.74(1 \mathrm{H}$, ddd, $J=10.1,7.9,5.5 \mathrm{~Hz}, \mathrm{H}-16)$, $2.99(1 \mathrm{H}, \mathrm{d}, J=15.9 \mathrm{~Hz}, \mathrm{H}-4 \mathrm{a}), 2.50(1 \mathrm{H}, \mathrm{d}, J=10.1 \mathrm{~Hz}, \mathrm{H}-17), 2.38(1 \mathrm{H}, \mathrm{d}$, $J=15.9 \mathrm{~Hz}, \mathrm{H}-4 \mathrm{~b}), 2.34(1 \mathrm{H}, \mathrm{dd}, J=16.8,5.2 \mathrm{~Hz}, \mathrm{H}-26 \mathrm{a}), 2.24(1 \mathrm{H}, \mathrm{dd}$, $J=16.8,7.33 \mathrm{~Hz}, \mathrm{H}-26 \mathrm{~b}), 1.59\left(3 \mathrm{H}, \mathrm{s}, 21-\mathrm{CH}_{3}\right), 1.28\left(3 \mathrm{H}, \mathrm{s}, 19-\mathrm{CH}_{3}\right), 1.08$ $\left(3 \mathrm{H}, \mathrm{d}, J=6.7 \mathrm{~Hz}, 27-\mathrm{CH}_{3}\right), 0.72\left(3 \mathrm{H}, \mathrm{s}, 18-\mathrm{CH}_{3}\right) ;{ }^{13} \mathrm{C}-\mathrm{NMR}\left(\mathrm{CDCl}_{3}\right) \delta$ 206.8 (C-3), 151.1 (C-22), 122.6 (5-CN), 118.8 (26-CN), 104.0 (C-20), 84.1 (C-16), 64.1 (C-17), 54.4 (C-14), 45.7 (C-5), 44.2 (C-4), 43.3 (C-13), 40.2 (C-9), 39.2 (C-12), 37.2 (C-10), 36.5 (C-1), 33.9 (C-8), 33.8 (C-2), 33.4 (C6), 33.2 (C-24), 31.1 (C-15), 30.0 (C-25), 26.0 (C-7), 24.4 (C-26), 23.1 (C11), 21.3 (C-23), 19.6 (C-19), 19.3 (C-27), 14.1 (C-18), 11.6 (C-21).

26-Cyanopseudodiosgenone (13), 5 $\alpha, 26$-Dicyanocolestan-3-one (14) and 5 $\boldsymbol{\beta}, 26$-Dicyanocolestan-3-one (15) from 9 The reaction of $9(200 \mathrm{mg}$, $0.38 \mathrm{mmol})$ with $\mathrm{NaCN}(75 \mathrm{mg}, 1.53 \mathrm{mmol})$ was performed for $2.5 \mathrm{~h}$ to obtain a residue. The resulting residue was subjected to preparative HPLC $\left(15 \% \mathrm{H}_{2} \mathrm{O}\right.$-acetone) to give $\mathbf{1 3}$ (54 mg: $33 \%$ yield) and a mixture. The mixture was subjected to preparative HPLC (DOCOSIL-B, 37.5\% $\mathrm{H}_{2} \mathrm{O}$-acetone) to give $14(20 \mathrm{mg}, 12 \%)$ and $\mathbf{1 5}(30 \mathrm{mg}, 17 \%)$. FAB-MS of 13: $\mathrm{m} / \mathrm{z} 444$ $[\mathrm{M}+\mathrm{Na}]^{+}$; FAB-MS $m / z$ : 422.3048 (Calcd for $\mathrm{C}_{28} \mathrm{H}_{39} \mathrm{O}_{2} \mathrm{~N}+\mathrm{H}$ : 422.3059); ${ }^{1} \mathrm{H}-\mathrm{NMR}\left(\mathrm{CDCl}_{3}\right)$ (only assignable signals were listed) $\delta: 5.73(1 \mathrm{H}, \mathrm{s}, \mathrm{H}-4)$, $4.74(1 \mathrm{H}$, ddd, $J=10.1,7.9,5.5 \mathrm{~Hz}, \mathrm{H}-16), 2.48(1 \mathrm{H}, \mathrm{d}, J=10.1 \mathrm{~Hz}, \mathrm{H}-17)$, 2.35 (1H, dd, $J=16.8,5.2 \mathrm{~Hz}, \mathrm{H}-26 \mathrm{a}), 2.24$ (1H, dd, $J=16.8,7.3 \mathrm{~Hz}, \mathrm{H}-26 \mathrm{~b})$, $1.59\left(3 \mathrm{H}, \mathrm{s}, 21-\mathrm{CH}_{3}\right), 1.20\left(3 \mathrm{H}, \mathrm{s}, 19-\mathrm{CH}_{3}\right), 1.09\left(3 \mathrm{H}, \mathrm{d}, J=6.7 \mathrm{~Hz}, 27-\mathrm{CH}_{3}\right)$, $0.72\left(3 \mathrm{H}, \mathrm{s}, 18-\mathrm{CH}_{3}\right) ;{ }^{13} \mathrm{C}-\mathrm{NMR}\left(\mathrm{CDCl}_{3}\right) \delta: 199.5(\mathrm{C}-3), 171.0(\mathrm{C}-5), 150.8$ (C-22), 123.9 (C-4), $118.7(\mathrm{CN}), 104.2$ (C-20), 84.2 (C-16), 64.0 (C-17), 54.1 (C-14), 53.7 (C-9), 43.3 (C-13), 39.3 (C-12), 38.6 (C-10), 35.7 (C-1), 35.0 (C-8), 33.9 (C-2), 33.1 (C-24), 32.7 (C-6 and C-15), 32.2 (C-7), 29.9 (C-25), 24.3 (C-26), 23.1 (C-11), 20.9 (C-23), 19.2 (C-27), 17.4 (C-19), 14.0 (C-18), $11.6(\mathrm{C}-21)$

26-Diethylaminopseudodiosgenone (21) The reaction of $9(200 \mathrm{mg}$, $0.38 \mathrm{mmol})$ with diethyl amine $(112 \mathrm{mg}, 1.53 \mathrm{mmol})$ was performed as described to obtain a residue. The resulting residue was purified by column chromatography (a gradient of $0-90 \%$ acetone in toluene) to give 21 (115 mg: $64 \%$ yield) as a semisolid. FAB-MS: $m / z$ $490[\mathrm{M}+\mathrm{Na}]^{+}$; FAB-MS $m / z$ : 468.3858 (Calcd for $\left.\mathrm{C}_{31} \mathrm{H}_{49} \mathrm{O}_{2} \mathrm{~N}+\mathrm{H}: 468.3842\right)$; ${ }^{1} \mathrm{H}-\mathrm{NMR}\left(\mathrm{CDCl}_{3}\right)$ (only assignable signals were listed) $\delta: 5.73(1 \mathrm{H}, \mathrm{s}, \mathrm{H}-4), 4.72(1 \mathrm{H}$, ddd, $J=10.1,7.6,5.5 \mathrm{~Hz}, \mathrm{H}-16), 2.48\left(4 \mathrm{H}, \mathrm{CH}_{2} \times 2, \mathrm{q}, J=7.3 \mathrm{~Hz}, \mathrm{NCH}_{2} \mathrm{CH}_{3}\right)$, $2.47(1 \mathrm{H}, \mathrm{d}, J=10.1 \mathrm{~Hz}, \mathrm{H}-17), 2.24(1 \mathrm{H}, \mathrm{dd}, J=12.5,5.8 \mathrm{~Hz}, \mathrm{H}-26 \mathrm{a}), 2.11$ $(1 \mathrm{H}, \mathrm{dd}, J=12.5,7.6 \mathrm{~Hz}, \mathrm{H}-26 \mathrm{~b}), 1.59\left(3 \mathrm{H}, \mathrm{s}, 21-\mathrm{CH}_{3}\right), 1.20(3 \mathrm{H}, \mathrm{s}, 19-$ $\left.\mathrm{CH}_{3}\right), 0.99\left(6 \mathrm{H}, \mathrm{CH}_{3} \times 2, \mathrm{t}, J=7.0 \mathrm{~Hz}, \mathrm{NCH}_{2} \mathrm{CH}_{3}\right), 0.90(3 \mathrm{H}, \mathrm{d}, J=6.4 \mathrm{~Hz}$, $\left.27-\mathrm{CH}_{3}\right), 0.72\left(3 \mathrm{H}, \mathrm{s}, 18-\mathrm{CH}_{3}\right) ;{ }^{13} \mathrm{C}-\mathrm{NMR}\left(\mathrm{CDCl}_{3}\right) \delta: 199.2(\mathrm{C}-3), 170.9(\mathrm{C}-$ 5), 152.1 (C-22), 123.7 (C-4), 103.0 (C-20), 83.9 (C-16), 64.0 (C-17), 60.0 (C-26), 54.1 (C-14), 53.6 (C-9), $47.3\left(\mathrm{NCH}_{2} \mathrm{CH}_{3}\right), 43.2$ (C-13), 39.2 (C-12), 38.5 (C-10), 35.6 (C-1), 34.9 (C-8), 33.9 (C-2), 33.8 (C-24), 32.7 (C-6), 32.3 (C-7), 31.0 (C-25), 23.3 (C-11), 20.8 (C-23), 18.2 (C-27), 17.3 (C-19), 13.9 (C-18), $11.5\left(\mathrm{C}-21\right.$ and $\left.\mathrm{NCH}_{2} \mathrm{CH}_{3}\right)$.

26-(Pyrrolidin-1-yl)pseudodiosgenone (22) The reaction of 9 (200 $\mathrm{mg}$, $0.38 \mathrm{mmol})$ with pyrrolidine $(108 \mathrm{mg}, 1.52 \mathrm{mmol})$ was performed as described to obtain a residue. The resulting residue was purified by column chromatography (a gradient of $0-90 \%$ acetone in toluene) to give $\mathbf{2 2}$ (48 mg: $27 \%$ yield) as a semisolid. FAB-MS: $m / z 466[\mathrm{M}+\mathrm{H}]^{+}$; FAB-MS $m / z: 466.3680$ (Calcd for $\mathrm{C}_{31} \mathrm{H}_{47} \mathrm{O}_{2} \mathrm{~N}+\mathrm{H}:$ 466.3686); ${ }^{1} \mathrm{H}-\mathrm{NMR}\left(\mathrm{CDCl}_{3}\right)$ (only assignable signals were listed) $\delta: 5.73(1 \mathrm{H}, \mathrm{s}, \mathrm{H}-4), 4.37(1 \mathrm{H}$, ddd, $J=10.1,7.9,5.8 \mathrm{~Hz}, \mathrm{H}-16), 2.47(1 \mathrm{H}, \mathrm{d}, J=10.1 \mathrm{~Hz}, \mathrm{H}-17), 2.40(2 \mathrm{H} \times 2, \mathrm{~m}$, pyrrolidine-2), $2.28(2 \mathrm{H}, \mathrm{d}, J=7.3 \mathrm{~Hz}, \mathrm{H}-26), 1.77(2 \mathrm{H} \times 2, \mathrm{~m}$, pyrrolidine3), $1.59\left(3 \mathrm{H}, \mathrm{s}, 21-\mathrm{CH}_{3}\right), 1.20\left(3 \mathrm{H}, \mathrm{s}, 19-\mathrm{CH}_{3}\right), 0.95(3 \mathrm{H}, \mathrm{d}, J=6.7 \mathrm{~Hz}, 27-$ $\left.\mathrm{CH}_{3}\right), 0.72\left(3 \mathrm{H}, \mathrm{s}, 18-\mathrm{CH}_{3}\right) ;{ }^{13} \mathrm{C}-\mathrm{NMR}\left(\mathrm{CDCl}_{3}\right) \delta: 199.3(\mathrm{C}-3), 171.0(\mathrm{C}-5)$ 152.2 (C-22), 123.8 (C-4), 103.2 (C-20), 84.0 (C-16), 64.1 (C-17), 63.6 (C26), 54.8 (pyrrolidine), 54.1 (C-14), 53.7 (C-9), 43.3 (C-13), 39.3 (C-12), 38.6 (C-10), 35.7 (C-1), 35.0 (C-8), 33.9 (C-2 and C-15), 32.8 (C-24), 32.7 (C-6), 32.2 (C-7), 32.0 (C-25), 23.4 (C-11, pyrrolidine), 20.9 (C-23), 18.3 (C-27), 17.3 (C-19), 14.0 (C-18), 11.6 (C-21)

26-Piperidnopseudodiosgenone (23) The reaction of 9 (200 mg, $0.38 \mathrm{mmol})$ with piperidine $(130 \mathrm{mg}, 1.52 \mathrm{mmol})$ was performed as described to obtain a residue. The resulting residue was purified by column chromatography (a gradient of $0-90 \%$ acetone in toluene) to give $\mathbf{2 3}$ (146 mg: $79 \%$ yield) as a semisolid. FAB-MS: $m / z 502[\mathrm{M}+\mathrm{Na}]^{+}$; FAB-MS $m / z: 480.3838$ (Calcd for $\left.\mathrm{C}_{32} \mathrm{H}_{49} \mathrm{O}_{2} \mathrm{~N}+\mathrm{H}: 480.3842\right) ;{ }^{1} \mathrm{H}-\mathrm{NMR}\left(\mathrm{CDCl}_{3}\right)$ (only assignable signals were listed) $\delta: 5.72(1 \mathrm{H}, \mathrm{s}, \mathrm{H}-4), 4.72(1 \mathrm{H}$, ddd, $J=10.1,7.9,5.8 \mathrm{~Hz}, \mathrm{H}-16), 2.47(1 \mathrm{H}, \mathrm{d}, J=10.1 \mathrm{~Hz}, \mathrm{H}-17), 2.29(2 \mathrm{H} \times 2, \mathrm{~m}$, piperidine-2), $2.11(1 \mathrm{H}, \mathrm{dd}, J=11.9,6.4 \mathrm{~Hz}, \mathrm{H}-26 \mathrm{a}), 2.02(1 \mathrm{H}, \mathrm{dd}, J=11.9$, $8.2 \mathrm{~Hz}, \mathrm{H}-26 \mathrm{~b}), 1.59\left(3 \mathrm{H}, \mathrm{s}, 21-\mathrm{CH}_{3}\right), 1.55(2 \mathrm{H} \times 2, \mathrm{~m}$, piperidine- 3$), 1.41$ $(2 \mathrm{H}, \mathrm{m}$, piperidine- 4$), 1.20\left(3 \mathrm{H}, \mathrm{s}, 19-\mathrm{CH}_{3}\right), 0.89(3 \mathrm{H}, \mathrm{d}, J=6.7 \mathrm{~Hz}, 27-$ $\left.\mathrm{CH}_{3}\right), 0.72\left(3 \mathrm{H}, \mathrm{s}, 18-\mathrm{CH}_{3}\right) ;{ }^{13} \mathrm{C}-\mathrm{NMR}\left(\mathrm{CDCl}_{3}\right) \delta: 199.3(\mathrm{C}-3), 171.0(\mathrm{C}-5)$, 152.3 (C-22), 123.9 (C-4), 103.2 (C-20), 84.0 (C-16), 66.3 (C-26), 64.1 (C17), 55.0 (piperidine), 54.2 (C-14), 53.7 (C-9), 43.3 (C-13), 39.3 (C-12), 38.6 (C-10), 35.7 (C-1), 35.0 (C-8), 34.0 (C-15), 33.9 (C-2), 32.8 (C-6 and C-24), 32.3 (C-7), 29.9 (C-25), 26.0 (piperidine), 24.6 (piperidine), 23.3 (C11), 21.0 (C-23), 18.4 (C-27), 17.4 (C-19), 14.0 (C-18), 11.6 (C-21).

26-Morpholinopseudodiosgenone (24) The reaction of $9(200 \mathrm{mg}$, $0.38 \mathrm{mmol}$ ) with morpholine $(132 \mathrm{mg}, 1.52 \mathrm{mmol})$ was performed as described to obtain a residue. The resulting residue was purified by column chromatography (a gradient of $0-50 \%$ acetone in toluene) to give $\mathbf{2 4}$ (135 mg: $73 \%$ yield) as a semisolid. FAB-MS: $m / z 482[\mathrm{M}+\mathrm{Na}]^{+}$; FAB-MS $m / z$ : 482.3618 (Calcd for $\mathrm{C}_{31} \mathrm{H}_{47} \mathrm{O}_{3} \mathrm{~N}+\mathrm{H}:$ 482.3635); ${ }^{1} \mathrm{H}-\mathrm{NMR}\left(\mathrm{CDCl}_{3}\right)$ (only assignable signals were listed) $\delta: 5.73(1 \mathrm{H}, \mathrm{s}, \mathrm{H}-4), 4.72(1 \mathrm{H}$, ddd, $J=10.1,7.9,5.8 \mathrm{~Hz}, \mathrm{H}-16), 3.69(2 \mathrm{H} \times 2, \mathrm{t}, J=4.0 \mathrm{~Hz}$, morpholine-2), 2.83 $(2 \mathrm{H} \times 2, \mathrm{t}, J=4.0 \mathrm{~Hz}$, morpholine-3), $2.47(1 \mathrm{H}, \mathrm{d}, J=10.1 \mathrm{~Hz}, \mathrm{H}-17), 2.17$ $(1 \mathrm{H}, \mathrm{dd}, J=12.2,4.9 \mathrm{~Hz}, \mathrm{H}-26 \mathrm{a}), 2.07(1 \mathrm{H}, \mathrm{dd}, J=12.2,7.6 \mathrm{~Hz}, \mathrm{H}-26 \mathrm{~b}), 1.59$ $\left(3 \mathrm{H}, \mathrm{s}, 21-\mathrm{CH}_{3}\right), 1.20\left(3 \mathrm{H}, \mathrm{s}, 19-\mathrm{CH}_{3}\right), 0.91\left(3 \mathrm{H}, \mathrm{d}, J=6.4 \mathrm{~Hz}, 27-\mathrm{CH}_{3}\right), 0.72$ $\left(3 \mathrm{H}, \mathrm{s}, 18-\mathrm{CH}_{3}\right) ;{ }^{13} \mathrm{C}-\mathrm{NMR}\left(\mathrm{CDCl}_{3}\right) \delta: 199.2(\mathrm{C}-3), 170.8(\mathrm{C}-5), 152.0(\mathrm{C}-$ 22), 123.7 (C-4), 103.2 (C-20), 83.9 (C-16), 66.9 (morpholine), 65.7 (C-26), 64.0 (C-17), 54.1 (C-14), 53.9 (morpholine), 53.6 (C-9), 43.2 (C-13), 39.2 (C-12), 38.5 (C-10), 35.6 (C-1), 34.9 (C-8), 33.8 (C-2 and C-15), 32.6 (C-6 and C-24), 32.2 (C-7), 29.3 (C-25), 23.3 (C-11), 20.8 (C-23), 18.0 (C-27), 17.3 (C-19), 13.9 (C-18), 11.5 (C-21). 
26-(4-Methylpiperazin-1-yl)pseudodiosgenone (25) The reaction of 9 (200 mg, $0.38 \mathrm{mmol}$ ) with 1-methylpiperazine (152 mg, $1.52 \mathrm{mmol}$ ) was performed as described to obtain a residue. The resulting residue was purified by column chromatography (a gradient of $0-100 \%$ acetone in toluene) to give 25 (115 mg: $61 \%$ yield) as a semisolid. FAB-MS: $m / z 495[\mathrm{M}+\mathrm{Na}]^{+}$; FAB-MS m/z: 495.3942 (Calcd for $\mathrm{C}_{32} \mathrm{H}_{50} \mathrm{O}_{2} \mathrm{~N}_{2}+\mathrm{H}$ : 495.3951); ${ }^{1} \mathrm{H}-\mathrm{NMR}$ $\left(\mathrm{CDCl}_{3}\right)$ (only assignable signals were listed) $\delta: 5.73(1 \mathrm{H}, \mathrm{s}, \mathrm{H}-4), 4.72(1 \mathrm{H}$, ddd, $J=10.4,7.9,5.8 \mathrm{~Hz}, \mathrm{H}-16), 2.47$ (1H, d, $J=10.4 \mathrm{~Hz}, \mathrm{H}-17), 2.42$ $(2 \mathrm{H} \times 4, \mathrm{~m}$, piperazine $), 2.30\left(3 \mathrm{H}, \mathrm{s}, \mathrm{NCH}_{3}\right), 2.17(1 \mathrm{H}, \mathrm{dd}, J=12.2,5.5 \mathrm{~Hz}$, H-26a), 2.08 (1H, dd, $J=12.2,7.9 \mathrm{~Hz}, \mathrm{H}-26 \mathrm{~b}), 1.59\left(3 \mathrm{H}, \mathrm{s}, 21-\mathrm{CH}_{3}\right), 1.20$ $\left(3 \mathrm{H}, \mathrm{s}, 19-\mathrm{CH}_{3}\right), 0.90\left(3 \mathrm{H}, \mathrm{d}, J=6.4 \mathrm{~Hz}, 27-\mathrm{CH}_{3}\right), 0.72\left(3 \mathrm{H}, \mathrm{s}, 18-\mathrm{CH}_{3}\right) ;{ }^{13} \mathrm{C}-$ NMR $\left(\mathrm{CDCl}_{3}\right) \delta: 199.3(\mathrm{C}-3), 170.9(\mathrm{C}-5), 152.0(\mathrm{C}-22), 123.7(\mathrm{C}-4), 103.2$ (C-20), 83.9 (C-16), 65.2 (C-26), 64.0 (C-17), 55.0 (piperazine), 54.1 (C14), 53.6 (C-9), 53.2 (piperazine), $45.9\left(\mathrm{NCH}_{3}\right), 43.2$ (C-13), 39.2 (C-12), 38.5 (C-10), 35.6 (C-1), 34.9 (C-8), 33.9 (C-15), 33.8 (C-2), 32.7 (C-24), 32.5 (C-6), 32.2 (C-7), 29.6 (C-25), 23.2 (C-11), 20.8 (C-23), 18.1 (C-27), 17.2 (C-19), 13.9 (C-18), 11.5 (C-21).

26-(1H-Imidazol-1-yl)pseudodiosgenone (27) The reaction of 9 (200 mg, $0.38 \mathrm{mmol})$ with imidazole $(104 \mathrm{mg}, 1.52 \mathrm{mmol})$ and $\mathrm{K}_{2} \mathrm{CO}_{3}$ (525 mg, $3.8 \mathrm{mmol}$ ) was performed as described to obtain a residue. The resulting residue was purified by column chromatography (a gradient of 0 $100 \%$ acetone in toluene) to give 27 (32 mg: $18 \%$ yield) as a semisolid and 11 (41 mg: $27 \%$ yield). FAB-MS of 27: $463[\mathrm{M}+\mathrm{H}]^{+}$; FAB-MS $m / z$ : 463.3322 (Calcd for $\mathrm{C}_{30} \mathrm{H}_{42} \mathrm{O}_{2} \mathrm{~N}_{2}+\mathrm{H}$ : 463.3325); ${ }^{1} \mathrm{H}-\mathrm{NMR}\left(\mathrm{CDCl}_{3}\right)$ (only assignable signals were listed) $\delta: 7.44(1 \mathrm{H}, \mathrm{s}$, imidazole-2), $7.05(1 \mathrm{H}, \mathrm{s}$, imidazole-4), $6.88(1 \mathrm{H}, \mathrm{s}$, imidazole-5), $5.73(1 \mathrm{H}, \mathrm{s}, \mathrm{H}-4), 4.73(1 \mathrm{H}$, ddd, $J=10.1,7.9,5.8 \mathrm{~Hz}, \mathrm{H}-16), 3.89$ (1H, dd, $J=13.7,5.8 \mathrm{~Hz}, \mathrm{H}-26 \mathrm{a}), 3,68(1 \mathrm{H}$, dd, $J=13.7,7.9 \mathrm{~Hz}, \mathrm{H}-26 \mathrm{~b}), 2.48(1 \mathrm{H}, \mathrm{d}, J=10.1 \mathrm{~Hz}, \mathrm{H}-17), 1.58(3 \mathrm{H}, \mathrm{s}, 21-$ $\left.\mathrm{CH}_{3}\right), 1.20\left(3 \mathrm{H}, \mathrm{s}, 19-\mathrm{CH}_{3}\right), 0.88\left(3 \mathrm{H}, \mathrm{d}, J=6.4 \mathrm{~Hz}, 27-\mathrm{CH}_{3}\right), 0.71(3 \mathrm{H}, \mathrm{s}$, $\left.18-\mathrm{CH}_{3}\right) ;{ }^{13} \mathrm{C}-\mathrm{NMR}\left(\mathrm{CDCl}_{3}\right) \delta$ : 199.4 (C-3), 170.9 (C-5), 151.0 (C-22), 137.4 (imidazole), 129.1 (imidazole), 123.8 (C-4), 119.3 (imidazole), 104.0 (C-20), 84.1 (C-16), 64.0 (C-17), 54.1 (C-14), 53.7 (C-9), 53.1 (C-26), 43.3 (C-13), 39.2 (C-12), 38.6 (C-10), 35.7 (C-1), 35.0 (C-8), 34.3 (C-25), 33.9 (C-2 and C-15), 32.7 (C-6), 32.2 (C-7), 31.4 (C-24), 23.0 (C-11), 20.9 (C23), 17.3 (C-27), 17.2 (C-19), 14.0 (C-18), 11.6 (C-21).

26-Azidopseudodiosgenone (31) The reaction of $9(200 \mathrm{mg}, 0.38$ mmol) with $\mathrm{NaN}_{3}(99 \mathrm{mg}, 1.52 \mathrm{mmol})$ was performed as described to obtain a residue. The resulting residue was subjected to preparative HPLC $(15 \%$ $\mathrm{H}_{2} \mathrm{O}$-acetone) to give $\mathbf{3 1}$ (103 mg: $61 \%$ yield) as a semisolid. FAB-MS: $m / z$ $438[\mathrm{M}+\mathrm{H}]^{+}$; FAB-MS $m / z$ : 438.3109 (Calcd for $\mathrm{C}_{27} \mathrm{H}_{39} \mathrm{O}_{2} \mathrm{~N}_{3}+\mathrm{H}$ : 438.3121); ${ }^{1} \mathrm{H}-\mathrm{NMR}\left(\mathrm{CDCl}_{3}\right)$ (only assignable signals were listed) $\delta: 5.72$ $(1 \mathrm{H}, \mathrm{s}, \mathrm{H}-4), 4.74(1 \mathrm{H}, \mathrm{ddd}, J=10.1,7.9,5.8 \mathrm{~Hz}, \mathrm{H}-16), 3.23(1 \mathrm{H}, \mathrm{dd}$, $J=11.9,5.5 \mathrm{~Hz}, \mathrm{H}-26 \mathrm{a}), 3.11(1 \mathrm{H}, \mathrm{dd}, J=11.9,7.0 \mathrm{~Hz}, \mathrm{H}-26 \mathrm{~b}), 2.49(1 \mathrm{H}, \mathrm{d}$, $J=10.1 \mathrm{~Hz}, \mathrm{H}-17), 1.59\left(3 \mathrm{H}, \mathrm{s}, 21-\mathrm{CH}_{3}\right), 1.20\left(3 \mathrm{H}, \mathrm{s}, 19-\mathrm{CH}_{3}\right), 0.97(3 \mathrm{H}, \mathrm{d}$, $\left.J=6.7 \mathrm{~Hz}, 27-\mathrm{CH}_{3}\right), 0.72\left(3 \mathrm{H}, \mathrm{s}, 18-\mathrm{CH}_{3}\right) ;{ }^{13} \mathrm{C}-\mathrm{NMR}\left(\mathrm{CDCl}_{3}\right) \delta: 199.2(\mathrm{C}-$ 3), 170.8 (C-5), 151.3 (C-22), 123.7 (C-4), 103.7 (C-20), 84.0 (C-16), 63.9 (C-17), 57.5 (C-26), 54.0 (C-14), 53.6 (C-9), 43.2 (C-13), 39.2 (C-12), 38.5 (C-10), 35.6 (C-1), 34.9 (C-8), 33.8 (C-2 and C-15), 32.9 (C-25), $32.6(\mathrm{C}-6)$, 32.2 (C-7), 23.0 (C-11), 20.8 (C-23), 17.4 (C-27), 17.3 (C-19), 13.9 (C-18), $11.5(\mathrm{C}-21)$.

2-((6R)-4,5,6,7-Tetrahydro-6-methyl-1H-1,2,3-triazepin-4-yl)pseudodiosgenone (32) from 31 A solution of $31(200 \mathrm{mg}, 0.46 \mathrm{mmol})$ in DMF $(20 \mathrm{ml})$ was heated at $120^{\circ} \mathrm{C}$ for $20 \mathrm{~h}$, and the mixture was evaporated. The resulting residue was subjected to preparative $\mathrm{HPLC}\left(30 \% \mathrm{H}_{2} \mathrm{O}\right.$-acetone) to give 32 (62 mg: $31 \%$ yield) as a semisolid. FAB-MS: $m / z 438[\mathrm{M}+\mathrm{H}]^{+}$; FAB-MS $m / z$ : 438.3117 (Calcd for $\mathrm{C}_{27} \mathrm{H}_{39} \mathrm{O}_{2} \mathrm{~N}_{3}+\mathrm{H}$ : 438.3121); ${ }^{1} \mathrm{H}-\mathrm{NMR}$ $\left(\mathrm{CDCl}_{3}\right)$ (only assignable signals were listed) $\delta: 5.73(1 \mathrm{H}, \mathrm{s}, \mathrm{H}-4), 4.92(1 \mathrm{H}$, ddd, $J=10.1,6.1,3.7 \mathrm{~Hz}, \mathrm{H}-16), 4.30(1 \mathrm{H}, \mathrm{t}, J=7.6 \mathrm{~Hz}, \mathrm{H}-23), 3.23(1 \mathrm{H}, \mathrm{dd}$, $J=11.9,5.8 \mathrm{~Hz}, \mathrm{H}-26 \mathrm{a}), 3.08$ (1H, dd, $J=11.9,7.0 \mathrm{~Hz}, \mathrm{H}-26 \mathrm{~b}), 2.03$ (2H, t, $J=7.6 \mathrm{~Hz}, \mathrm{H}-24), 1.99$ ( $1 \mathrm{H}, \mathrm{d}, J=6.4 \mathrm{~Hz}, \mathrm{H}-17), 1.79$ (1H, m, H-25), 1.52 $\left(3 \mathrm{H}, \mathrm{s}, 21-\mathrm{CH}_{3}\right), 1.18\left(3 \mathrm{H}, \mathrm{s}, 19-\mathrm{CH}_{3}\right), 0.95\left(3 \mathrm{H}, \mathrm{d}, J=6.7 \mathrm{~Hz}, 27-\mathrm{CH}_{3}\right), 0.84$ $\left(3 \mathrm{H}, \mathrm{s}, 18-\mathrm{CH}_{3}\right) ;{ }^{13} \mathrm{C}-\mathrm{NMR}\left(\mathrm{CDCl}_{3}\right) \delta: 199.4(\mathrm{C}-3), 170.8(\mathrm{C}-5), 162.7(\mathrm{C}-$ 22), 123.8 (C-4), 91.1 (C-23), 83.8 (C-16), 77.3 (C-20), 66.1 (C-17), 57.3 (C-26), 55.9 (C-14), 53.3 (C-9), 40.1 (C-13), 38.6 (C-12), 38.4 (C-10), 35.5 (C-1), 34.5 (C-8), 34.1 (C-25), 33.8 (C-2), 32.8 (C-15), 32.6 (C-6), 31.8 (C7), 29.4 (C-24), 21.1 (C-21), 20.1 (C-11), 17.6 (C-27), 17.2 (C-19), 13.1 (C18).

Cytotoxic Activities. Cell Lines and Culture The human colorectal caricinoma cell line (HCT 116, ATCC No. CCL-247) and human hepatoma cell line (Hep G2, No. RCB0459) were purchased from Dainippon Pharmaceutical Co. LTD (Osaka, Japan) and RIKEN Cell Bank (Tsukuba, Japan), respectively. Dulbecco's Modified Eagle's medium (DMEM), McCoy's 5A medium, fetal bovine serum (FBS) and the penicillin-streptomycin mixture were purchased from Wako Pure Chemical Industries Ltd. (Osaka, Japan),
Sigma (MO, U.S.A), Biosource International (CA, U.S.A) and Bio Whittaker (ND, U.S.A), respectively. The HCT 116 cells and Hep G2 cells were maintained in McCoy's 5A medium and in DMEM, respectively. Each medium was supplemented with $10 \%$ FBS and the penicillin-streptomycin mixture (100 U/ml penicillin and $100 \mathrm{mg} / \mathrm{ml}$ streptomycin) at $37^{\circ} \mathrm{C}$ in a humidified atmosphere containing $5 \% \mathrm{CO}_{2}$.

Assay Procedure The ability of the drug to inhibit cellular growth was determined using the MTT assay. ${ }^{22)}$ The cytotoxicity of test drugs was assessed as previously described. ${ }^{28)}$ Each experiment was performed in duplicate wells, and all experiments involved a control (DMSO only). The drug treatments were performed separately 3 times. Data represent mean \pm S.D. values.

Antibacteridal and Antifungal Activities Test Organisms: Bacillus subtilis IFO 3134, Staphylococcus aureus IFO 12732, Escherichia coli IFO 3972, Pseudomonas aeruginosa IFO 13275, Candida albicans IFO 1594 and Aspergillus niger IFO 9455 were purchased from the Institute for Fermentation (Osaka, Japan).

Assay for Antibacterial Activities: Assays for activity against gram-positive (B. subtilis, S. aureus) and gram-negative (E. coli, P. aeruginosa) bacteria were carried out by the micro dilution method according to the NCCLS documents M7-A5. ${ }^{25}$ ) The bacterial strains were maintained on trypticase soy agar at $27^{\circ} \mathrm{C}$. The test compounds in DMSO were diluted with Mueller Hinton II broth (cation adjusted) to give serial 2-fold dilutions in the range $500-3.9 \mu \mathrm{g} / \mathrm{ml}$. The presence of DMSO in the assay medium (maximum concentration $5 \%$ ) did not affect the growth of the bacteria. The inoculum was standardized by adusting to $1 \times 10^{6} \mathrm{CFU} / \mathrm{ml}$ for each bacterium. The minimal inhibitory concentration (MIC) was estimated after incubation at $37^{\circ} \mathrm{C}$ for $24 \mathrm{~h}$. Each experiment was performed in duplicate well and drug treatments were performed separately 3 times.

Assay for Antifungal Activities: Antifungal assays were carried out by the micro dilution method according to the NCCLS doucuments M27-A for Candida and H38-P for Aspergillus. ${ }^{26,27)}$ Strains of A. niger and C. albicans were maintained on potato dextrose agar and Sabouraud dextrose agar, respectively, at $27^{\circ} \mathrm{C}$. Test compounds in DMSO were diluted with RPMI 1640 medium to give serial 2-fold dilutions in the range $500-3.9 \mu \mathrm{g} / \mathrm{ml}$. The growth of tested fungus was not affected by the presence of DMSO (maximum concentration 5\%). The inoculum was standardized by adjusting to $8 \times 10^{4} \mathrm{CFU} / \mathrm{ml}$ for $A$. niger and to $2.5 \times 10^{3} \mathrm{CFU} / \mathrm{ml}$ for $C$. albicans. MIC was estimated after incubation at $27^{\circ} \mathrm{C}$ for $48 \mathrm{~h}$. Each experiment was performed in duplicate wells and drug treatments were performed separately 3 times.

\section{References}

1) Hayashi K., Wada K, Mitsuhashi H., Bando H., Takase M., Terada S., Koide Y., Aiba T., Narita T., Mizuno D., Chem. Pharm. Bull., 28, 1954-1958 (1980).

2) Mita A., Shida R., Kasai N., Shoji J., Biomedicine, 31, 223-227 (1979).

3) Cuellar M. J., Giner R. M., Recio M. C., Just M. J., Manez S., Cerds M., Hostettmann K., Rios J.-L., Nat. J. Prod., 60, 1158-1160 (1997).

4) Ito M., Nakashima H., Baba M., Shigeta S., Yamamoto N., Igaku no Ayumi, 141, 427-428 (1987).

5) Ito M., Nakashima H., Baba M., Shigeta S., Yamamoto N., Chem. Abstr., 107, 89374y (1987).

6) Saito S., Kuroda K., Hayashi Y., Nagamura Y., Nishida K., Ishiguro I., Chem. Pharm. Bull., 39, 2333-2339 (1991).

7) Saito S., Sumita S., Kanda Y., Sasaki Y., Tetrahedron Lett., 33, 73817384 (1992).

8) Saito S., Sasaki Y., Kuroda K., Hayashi Y., Sumita S., Nagamura Y., Nishida K., Ishiguro I., Chem. Pharm. Bull., 41, 539-543 (1993).

9) Saito S., Ebashi J., Sumita S., Furumoto T., Nagamura Y., Nishida K., Ishiguro I., Chem. Pharm. Bull., 41, 1395-1401 (1993).

10) Saito S., Sumita S., Kanda Y., Sasaki Y., Chem. Pharm. Bull., 42, 1016-1027 (1994).

11) Saito S., Sumita S., Furumoto T., Ebashi J., Nagamura Y., Ishiguro I., Eur. J. Med. Chem., 29, 455-470 (1994).

12) Saito S., Nagase S., Kawase M., Nagamura Y., Eur. J. Med. Chem., 31, 557-574 (1996).

13) Saito S., Furumoto T., Ochiai M., Hosono A., Hoshino H., Haraguchi U., Ikeda R., Shimada N., Eur. J. Med. Chem., 31, 365-381 (1996).

14) Beaton J. M., Spring F. S., J. Chem. Soc., 1955, 3126-3129.

15) Quan H.-J., Koyanagi J., Ohmori K., Uesato S., Tsuchido T., Saito S., Eur. J. Med. Chem., 37, 659-669 (2002).

16) Uhle F. C., J. Org. Chem., 27, 2797-2799 (1962). 
17) Uhle F. C., J. Org. Chem., 32, $792-797$ (1967).

18) Uhle F. C., J. Org. Chem., 32, 1596-1601 (1967).

19) Shionoya M., Jimbo T., Kitagawa M., Soga T., Tohgo A., Cancer Sci., 94, 459-466 (2003)

20) Lee G., Piqette-Miller M., Can. J. Physiol. Pharmacol., 79, 876-884 (2001).

21) Takara K., Sakaeda T., Tanigawara Y., Nishiguchi K., Ohmoto N., Horinouchi M., Komada F., Ohnishi N., Yokoyama T., Okumura K., Eur. J. Pharm. Sci., 16, 159-165 (2002)

22) Mosmann T., J. Immunol. Methods, 65, 55-63 (1983).
23) Tsuchido T., Takeuchi H., Kawahara H., Obata H., J. Fermen. Bioeng., 78, 183-187 (1994).

24) Tsuchido T., Yasunaga K., Matsumura Y., Oku K., Biocontrol Sci., 1, 61-63 (1996).

25) National committee for clinical laboratory standards. 2000, M7-A5.

26) National committee for clinical laboratory standards. 1997, M27-A.

27) National committee for clinical laboratory standards. 1998, M38-P.

28) Jin G.-Z., Quan H.-J., Koyanagi J., Takeuchi K., Miura Y., Komada F., Saito S., Cancer Lett., 218, 15-20 (2005). 